\title{
The State of the Health (Dis)-Union in the EU: the legacy of austerity under the trial of Covid-19
}

\author{
Carlo Maria Palermo ${ }^{1}$, Matilde Ceron ${ }^{2}$
}

\begin{abstract}
Covid-19 has brought under the spotlight contradictions and inadequacy of EU governance against the cross-border pandemic challenge. Health policy remains a near exclusive national competence, only carving within the Treaties limited supranational coordination. Meanwhile, the detrimental social effects of the EMU austerity paradigm, especially for weaker Southern economies, did not spare healthcare spending. From a public policy theoretical perspective the framework screams sub-optimality if not outright inadequacy against transnational health challenges, within the highly interdependent regionally integrated European Union. With early cries for improved cooperation and coordination crashing against limited institutional capacity and decision-making power at the supranational level, proposals for a Health Union have risen within the policy debate.

Nevertheless, there is a lack of comprehensive empirical assessment of how the pandemic highlights the limits of the current framework and the extent to which such shortcomings are resolved by governance transformations currently on the table. The contribution extends the understanding of the socio-economic inequalities and implications of the lack of an effective EU public health competence considering from a comparative perspective (austerity induced) geographic heterogeneities in healthcare preparedness, outbreak, crisis management and outcomes, delineating the extent to which inequalities remain in the absence of a Health Union. By way of Principal Component Analysis within the multidimensionality of the pandemic we uncover the connection between input factors (e.g. hospitals beds, healthcare spending, etc.), outbreak dynamics (e.g. cases, restrictions, testing and tracing policies, etc.) and outcomes (e.g. GDP, mortality, etc.).

The analysis highlights how the Covid-19 case has further evidenced the unfitness of the current governance framework in the health domain, leaving the EU with limited coordination even in the core transnational domain of public health. Qualitatively, we map findings within the political EU and national context extending not only a preliminary policy evaluation on the way forward towards a Health Union but also an empirically grounded case for sovereignty pooling and a feasible blueprint within the roadmap of the Conference on the Future of Europe.
\end{abstract}

\footnotetext{
${ }^{1}$ Member of the Scientific Committee Centro Studi Problemi Internazionali (CESPI)

2 Postdoc, University of Pavia, Department of Political and Social Sciences
} 


\section{Introduction}

The attention to EU health policy and the Union role in public health has been growing both within the academic and policy debate, coming to the forefront with the Covid-19 outbreak. Such a development has followed the progression of the EU role and policies in the health domain, initially expanded especially through common market-based competencies. In addition, jurisprudence, also through the common-market legal basis of the four freedoms, established mobility rights both on the side of providers and patients (Brooks, 2012). In the post-Lisbon era, the scope for EU health law and policy - itself what has been portrayed as "patchwork" concept spanning several (limited) competencies across domains ranging from the market, the social arena, the narrower public health field and fiscal policies (Guy, 2017, p.17) - has been further expanded through the Open Method of Coordination, reaching in more recent years further prevalence in the context of the Semester and Country Specific Recommendations as well as in the context of the austerity-driven pressure exerted on national budgets. The implication is that the limited scope for action at the Union level is fragmented across several legal bases rather than the result of an intentional shift of competencies to the supranational level or even a well-designed linearly evolving effective coordination role in the area of transnational interests (e.g. Lamping, 2013; Guy, 2017). As a result, limited competencies have been expanded in practice, intertwined within the broader complex net of the multilevel governance framework of the European Union.

From such a perspective a further complication is the high diversity and fragmentation encompassed by the health arena per se - within which the most relevant distinction is across healthcare and public health. Nevertheless, the two areas are far from independent silos, as they carry intra and inter implications within the health domain (e.g. healthcare capacity for public health) or concerning other policy areas (e.g. fiscal discipline compressing health public spending). The result is a complex and multidimensional environment in which at the same time the EU level may have broader implications than expected at face value (e.g. austerity policies weakening health preparedness) while maintaining little effectiveness in areas in which some formal albeit limited competence exist (e.g. public health coordination). Against such a backdrop, limited competencies cannot per se imply disregarding any impact from the EU level (e.g. austerity) or coordination when sought to address problems the Member States may see added value in addressing jointly through the assistance and support of the institutions (e.g. past public health emergencies) suggesting formal and actual scope for EU action may far from perfectly align (De Ruijter, 2019).

As a result, a long-standing argument sees an involuntary erosion over time of full national control over health policies (e.g. Greer, 2006, 2012). That has been especially the case in the aftermath of the Great Recession and Eurozone crisis, with austerity policies often claimed to negatively impact not only social but also health capacity and outcomes. This may have worsened health convergence within the EU, something for which there is limited evidence pre-crisis indicating that health may not have necessarily followed its economic counterpart (Kerem et al., 2008; Lau et al., 2014). As a result, health inequalities within and across the Member States have remained substantial overtime (Marnot, 2013; Santos et al., 2020; Rokicki et al., 2021), arguably worsened by the Great Recession and the Eurozone crisis and the EU austerity response (van der Wel et al., 2018). A renewed centrality of health within the debate has hence emerged surrounding the crisis both given the overall challenge of budgetary discipline and ensuring sustainability in healthcare spending trends especially given the budgetary pressures of consolidation on one side and demography and ageing on the latter (Seychell and Hackbart, 2013). At the same time, the broader question has been raised of the added value of EU action (Clemens et al., 2014), especially relevant in public health as a transnational issue with relevance for several existing policy areas (Verschuuren et al., 2013; Greer, 2020b; Greer and Holly, 2021). 
In this context, the Covid-19 pandemic has brought health policy and especially public health unprecedentedly at the centre stage, well beyond the academic debate. Indeed, public health and investment in healthcare have gained exorbitant salience both at the national and supranational levels, as Member States proceeded with emergency investment in the heat of the crisis, a special line of the European Stability Mechanism was deployed at the EU level to support emergency health investment and the arena made its way among the pillars of the Next Generation EU pandemic recovery plan. At the same time, the Covid-19 crisis led to a revisiting of the assessment of the need for greater coordination and integration at the EU level, to which this work contributes. Within the broad argument that this domain is one especially likely to develop predominantly under the pressure of the crisis (Greer et al., 2021a), some have highlighted the limited scope of coordination in the current governance framework (Brooks et al., 2020; Renda and Castro, 2020), while other the presence of some solidarity especially concerning vaccines (Greer, 2020a). Several authors have explored the contribution of the pandemic to increased coordination in public health and health policy more broadly. Analyses have considered comparatively the current context and past developments to raise expectations on reform and decision-making to follow the Covid-19 crisis (Brooks \& Greyer, 2020). Such reasoning is parallel by considerations that expands to the analysis of the allocation of decision making across levels of governments within the Member States (Greer et al., 2020b).

The paper fits within this unfolding debate on the pandemic as a catalyst for integration both in highlighting the limits of health governance against transnational challenges and the problem of existing inequalities in health preparedness, worsened in the recent years at the hand of austerity policies. At the same time, in evidencing the enormous scale of challenges and the limited scope for EU competencies within the current Treaties, we highlight the limits of current reform proposals. From such a perspective, the argument is that Covid-19 is a perfect case of the unfitness of EU health governance, especially given the interdependence in a transnational public health crisis, as high levels of pre-existing (worsening) inequalities together with fragmented responses fostered by the absence of transnational solidarity and coordination within the Union are a threat to effective crisis management and timely exit from the crisis. The implication is a need for further integration which goes beyond the scope of the Treaties and current policy proposals fostered by the pandemic such as the Health Union.

In supporting the argument we carry out a mixed-methods analysis, comparing quantitatively indicators of health preparedness, pandemic response and outcomes across the EU27, seeking to further evidence their linkages through Principal Component analysis. At the same time we consider on a qualitative level (i) dynamics after the crisis and their role in shaping the unequal preparedness to face the pandemic (ii) the EU health governance framework, its limited scope for coordination and recent developments in tackling Covid-19 and the (iii) the health reform proposals currently on the agenda. In doing so we assess three research questions:

[1] Whether the pre-pandemic context is characterized by high levels of cross-country inequalities in health yielding different levels of pandemic preparedness and signalling a governance framework ill-equipped to foster convergence;

[2] Whether Covid-19 responses across the EU27 were fragmented indicating limited EU coordination and cross-country variation in the effectiveness of crisis management and the implication linkages across inputs outputs and outcomes for the fragility of integration;

[3] Whether the need for further integration indicated by the Covid-19 crisis can be satisfied within the scope of the Treaties and current reform proposals such as the Health Union. 


\section{The health legacy of the Great Recession and austerity}

A prolific stream of the literature on EU economic governance has been dedicated to the Great Recession and austerity policies. In this context, austerity policies have been portrayed as detrimental to the recovery, lengthening and deepening the Great Recession. In this regard, EU governance in the Great Recession and Eurozone crisis has been labelled as "a near-perfect case of mismanagement" (Wyplosz, 2017, p.45). Beyond the negative impact on growth and the economy, the cost of austerity has been highlighted in the social arena and terms of the increasing divergence between the northern core and the southern periphery of Europe (Howarth and Verdin, 2020; Makszin et al., 2020). Negative social outcomes span from an austerity-driven increase in youth unemployment, especially in high debt countries (Marques and Hörisch, 2020), to the worsening of gender parity (Perugini et al., 2019). In this context, the welfare state has been a key target of the budgetary diet (Crespy, 2015; De La Porte and Heins, 2015; Andor, 2017) to the extent that austerity policies may downsize "social citizenship" to the altar of budgetary prudence (Greer \& Jarman, 2018, p. 76). Primarily in the periphery EU pressure supported reforms liberalising the labour market and curtailing the generosity of benefits (e.g. Bulfone and Tassinari, 2020). In parallel, EU determinants such as recommendations within the Semester and EDP surveillance have grown in importance over domestic factors, for example in pension reforms (Guardiancich and Guidi, 2020).

The burden of the Great recession was hence heavily tilted to the disfavour of the periphery (Censolo and Colombo, 2016; Jones et al., 2016; De Grauwe and Ji, 2018; Terzi, 2020), to the point that it even pressured migration patterns from Southern to Northern countries (Mattijs and Merler, 2020). Indeed, countries in the periphery were pressured into reducing public spending and enacting strict austerity measures and enact structural reform aimed at Europeanising their economies toward growth, limiting national sovereignty over public finances and worsening the democratic deficit of the EU, the trust of citizens and the support for integration and democracy (e.g. Della Porta, 2015; Notermans and Piattoni, 2020; Pagoulatos, 2020; Papadopoulous, 2020; Crespy, 2020). Within this context, the periphery had to liberalise the labour market (Burlone and Tassinari, 2020) and external pressure gave way to substantial public sector reforms (Mascio et al., 2020), at a high social cost (Guillénn et al., 2016). As a result, the EU economic governance has been shown to contribute to destabilising the periphery both in its economic reality and in the perception of citizens, favouring the rise of Euroscepticism (Armingeon et al., 2016; Ruiz-Rufino and Alonso, 2017; Matthijs, 2017; Papadopoulos and Roumpakis, 2018; Notermans and Piattoni, 2020).

Such dynamics are of relevance also for the domain of interest of the analysis: health. Differences across the Member States are as long-standing as the Union, given the high level of cross-country heterogeneities in one of the primary determinants of health spending - GDP (Lau et al., 2014; Villaverde et al., 2014). In this context, the question of convergence has emerged early in the integration process also in this domain. In the pre-crisis period mixed - weak at best - evidence of convergence suggests that any progress may be limited both in terms of GDP and per capita (Lau et al., 2014; Villaverde et al., 2014). Ahead of Covid-19 core policy debate in the context of health spending - in the context of its continued growth and the worries linked to population ageing - has long remained, however, sustainability. In this context, the pressure rose on getting the growth of healthcare spending under control during the crisis and as austerity policies toward fiscal discipline took over the continent and especially the periphery (Quaglio et al., 2013).

In this context, the literature has considered the impact of crises and the Great Recession specifically on health across several dimensions. In terms of health outcomes, analyses at the individual level considered increased risk associated with unemployment as well as implications for overall health inequalities. On the latter account, evidence of increasing health inequalities has gone beyond uncovering the role of the recession per se, indicating the powerful role of austerity policies which are detrimental for health outcomes even in their own right (Toffolutti and Suhrcke, 2019). The dangerous 
tandem has worsened health outcomes especially for those with disadvantaged socio-economic backgrounds, resulted in additional pressure on the health system spread thin by budget cuts and have been even associated with the increased spread of infectious diseases (Karanikolos et al., 2013; Stuckler et al., 2017; van der Wel et al., 2018). Indeed, not only are vulnerable groups more exposed to the risks associated with the recession but are also especially impacted by cuts to the health budget as they are more reliant on public services. The extent of such an effect is dependent on the pre-existing strength of the welfare system and health services specifically (Marmot et al., 2013). Hence, countries affected the most by the bind of austerity and lagging behind to begin with - as in Southern Europe experienced increasing inequalities both across and within the country, generating a widening gap over time (van der Wel et al., 2018). An effect that has been shown to be long lasting (Antonova et al., 2017).

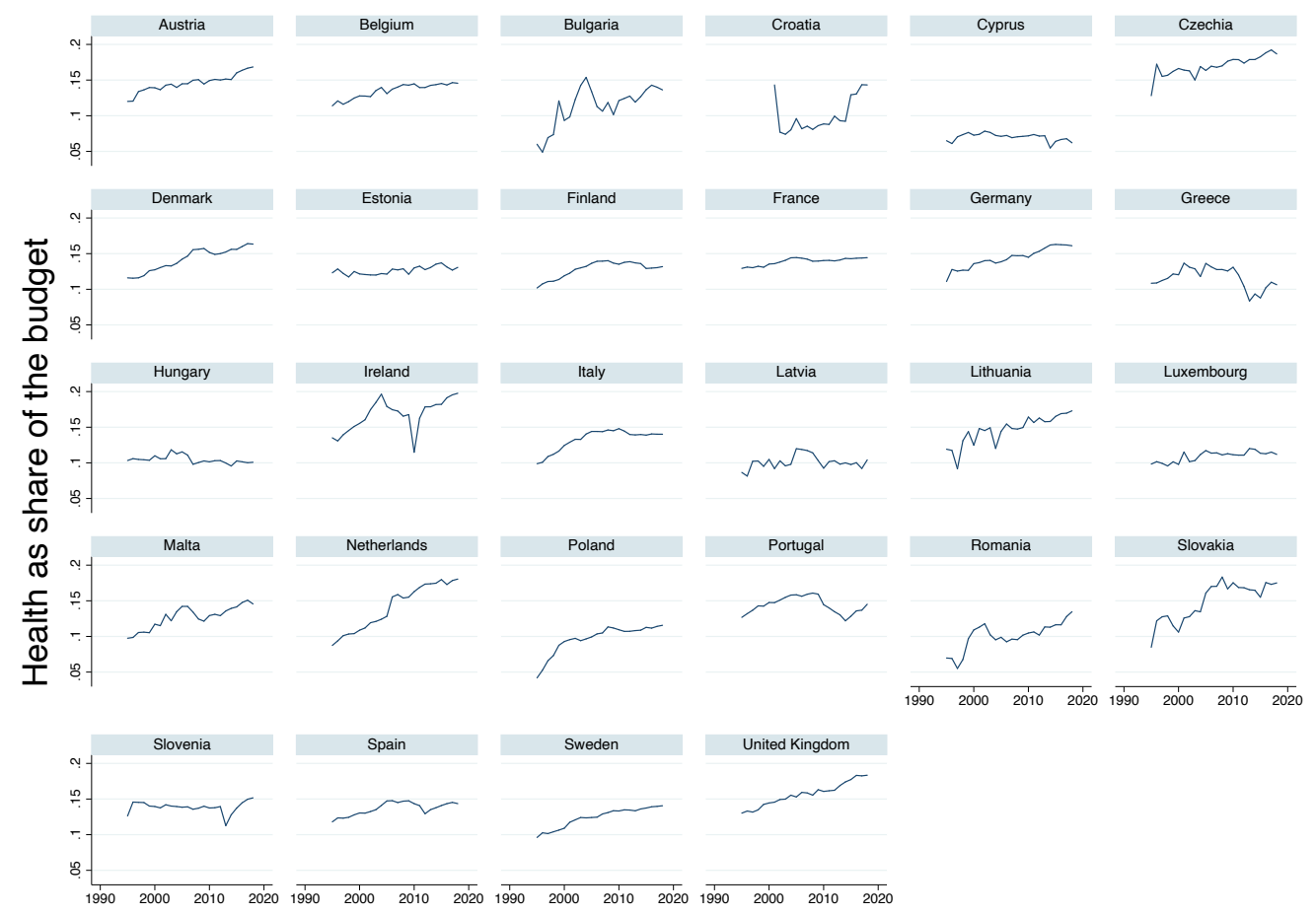

Figure 1 - The evolution of health spending as a share of public spending

Such a background paints the picture of an expanding divide for healthcare and its preparedness across the Union. A dynamic to which the EU and its mandated austerity policies in the periphery may have heavily contributed (Forster and Kentikelenis, 2019). Visualising trends in health spending across the Union confirm the divide and trend. Figure 1 shows the evolution of health spending as a share of the budget in the last two decades across the EU28. Differences are extensive and they are not only limited to the starting and/or endpoint of the weight of health on public spending. Trends also vary substantially. Some countries, such as Austria, Belgium, Germany, the Netherlands, Sweden and the UK show a fairly continuous upward trend in the prevalence of the health budget component. That is to say, the share of health spending in the public budget in those core countries has been systematically and steadily increased over the years, including during and after the Great Recession. Central and Eastern European countries show higher heterogeneities in trends, generally starting from lower shares. For some countries the dynamic is increasing but not without periods of consolidations (e.g. Bulgaria, Romania and Slovakia) especially in the early side of the timeline. Others like Hungary and Latvia are essentially flat except for an increasing bout in the years preceding and following the crisis. A fairly homogeneous trend emerges conversely in the South of Europe. Except for Cyprus fairly stable over time at a low share, the block experiences an initial upward trend - one which is interrupted by the crisis. In some countries, the contraction or stagnation never reversed (e.g. Italy), while in all except Malta even if it did the pre-crisis share was not recovered by 2018. Considering instead the trends in health 
spending as a function of GDP in Figure 2, the picture is similar: high heterogeneities in starting and end-points as well as in trends. Similarly, the South of Europe - together with other countries experiencing the austerity pressure of a Memorandum such as Ireland - experienced the worst contraction in the context of the Eurozone Crisis. From a GDP perspective, the trend is unanimous among Southern Member States post-crisis: while the steepness of the drop in the context of the Euro crisis varies, no country fully recovered the level of healthcare spending pre-crisis in the periphery. That is to say, austerity in practice looks like years of contractions in health spending especially in the South of Europe, often never rebounding upward post-crisis. The result is that the years preceding the pandemic were characterised by widespread health budget cuts in the periphery, at a steep rate in many instances for a prolonged time during the last decade and often never reversed, leading to a potentially substantially weakened healthcare infrastructure.

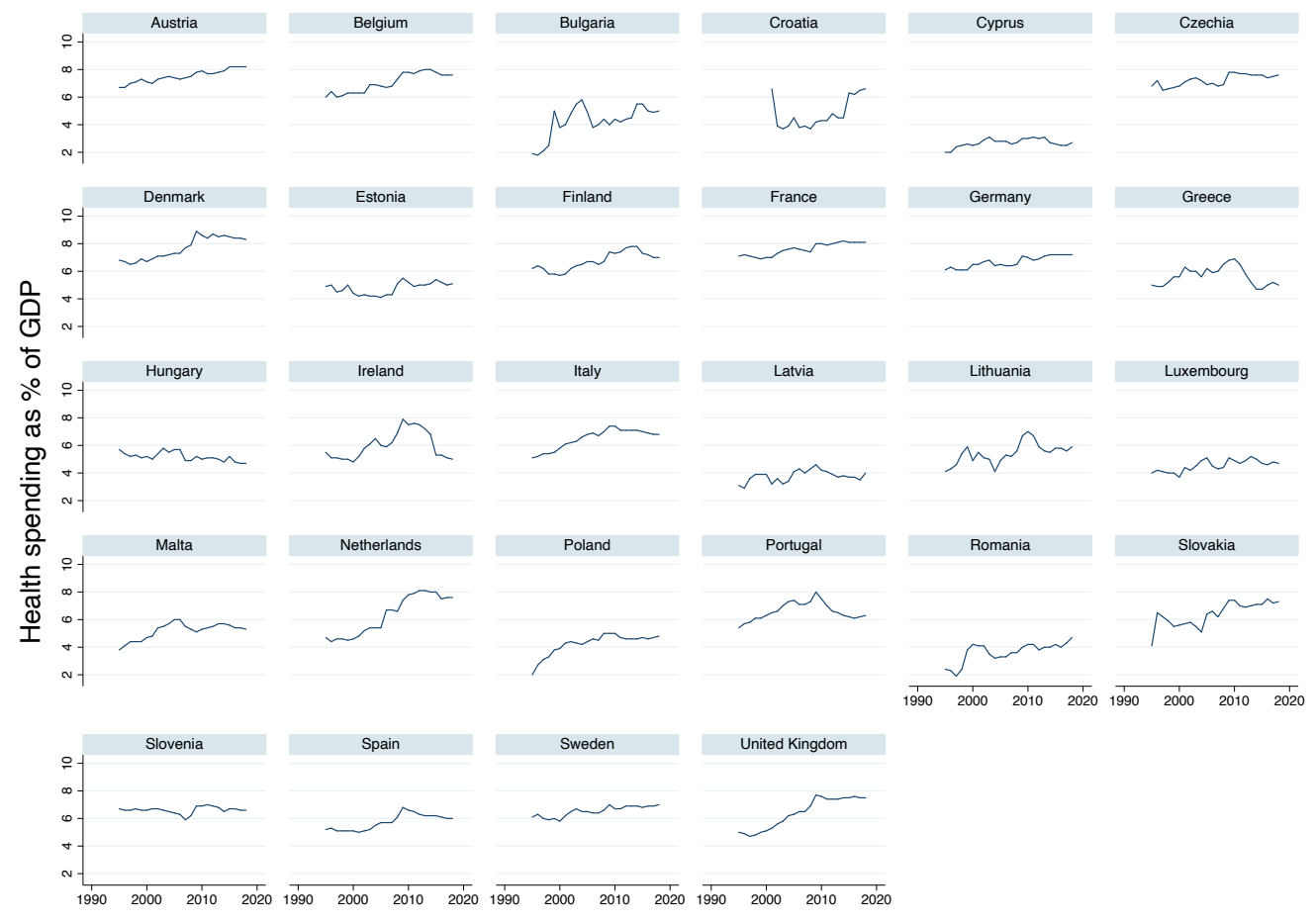

Figure 2 - The evolution of health spending as a percentage of GDP

The growing divide between the core and periphery - which was already a worrisome and destabilising matter in the context of the Euro Crisis and its aftermath - has regained centre stage in the Covid-19 pandemic given the further widening of the gap between Northern and Southern Member States (e.g. Camous and Claeys, 2020; Celi et al., 2020; Howarth and Verdun, 2020; Gräbner et al., 2020). As a result, austerity - dubbed by some as a "failed experiment on the people of Europe" (Holland, 2012, p.346) - may have left behind a dramatic and far-reaching legacy in the context of the current crisis. Directly, it has left the periphery with weaker healthcare systems in the face of the outbreak. Indirectly, the unpreparedness in the health domain has implied spillovers for the policy mix available to governments in managing the crisis. As more - economically costly - restrictions are necessary to mitigate a tragic body count as health services reach overcapacity, the South of Europe has concomitantly more limited fiscal space to deploy in response. The result is that of "unequal scars" resulting from the Covid-19 crisis (Schanbe, 2020), feeding into a vicious cycle of long-lasting geographical divides and inequalities. A predicament - considered empirically in the sections to follow which strongly backs solidarity and coordination across the Member States not only in the economic but also in the health arena. As we proceed to illustrate in the domain of interest, this work is an impossible challenge in the current governance context. 


\section{The EU health governance framework}

Public health gained a central role in public debate. Europe is still the area of the world where health is generally a public good for most of the European citizens. The European Union placed among its fundamental rights "Right to health". The art.35 of the European Charter of Human Rights reserved a special place for Healthcare in the "Solidarity" chapter, belonging to the existing constitutional mores of many Member States and the European Social Model and tradition (ECFR, 2000).

Nevertheless, despite such a solemn statement, the EU narrowly reserved health. Indeed, art. 168 establishes subsidiarity in favour of the Member States. Just consultation is allowed to the European level, while the Member States retained exclusive competencies on this chapter. Thus, the public health organisation is an exclusive national competence, while Europe is going to complete this chapter acting on transnational threats (Treaty on Functioning of the European Union, 2). As widely demonstrated, Member States have always been reluctant to cede sovereignty in such a domain (Greer, \& Löblová, 2016). To explain such a posture, we could consider the delicate position of health in nation-state social policy and its intimate links to responsiveness and legitimacy. We should never forget the intimate linkage between health and national welfare politics: indeed, health policy is funded by national fiscal policy, legitimated by the legislative bodies and, very often, many of those powers are delegated to the subnational entities (e.g. regions and federate states).

Nevertheless, such a posture produced an unequal system. As demonstrated by the OECD, the overall level of care in the European Union is good, but several Member States underperform in different fields (OECD, 2020). Many inequalities are due to socioeconomic conditions, income disparities, divergences in fiscal policies, growing unemployment (Forster et al., 2018; Eikemo et al., 2017). Moreover, the periphery experimented with higher levels of unmet need of medical care fuelling persisting income division in Europe (Forster et al., 2018: 46). The inequalities are linked to lower employment in the periphery of the European Union as unmet health needs are linked with unemployment. Such differences have been exacerbated by austerity (Forster et al., 2018).

Substantial differences are paralleled in ICU-bed distribution, a key asset during the Covid-19 crisis. Germany holds a higher number of beds and ICUs (Rhodes et al., 2012). Other countries like Italy, Spain and France have more limited capacity - a shortage which during the pandemic has been dramatic for emergency care (Rhodes et al., 2012). Moreover, a research-based on fewer countries, Italy, Germany, France, Slovenia, Croatia, England, Slovakia, Austria, Poland, Estonia, Denmark and Lithuania, confirmed the primacy of Germany in terms of ICU, weakness of France, Denmark and Italy, along with the relative strength of Slovakia, Estonia and Lithuania (Annan et al., 2021). Italy and France, moreover, experienced a higher difference between urban context and countryside (Bauer et al., 2020)

Data showed also how unequal the distribution of health professionals is within the EU: Germany, Denmark and Sweden have a high distribution of doctors and nurses, while Italy, Portugal and Spain have a higher number of doctors and lower of nurses; Central European countries have lower numbers of doctor and nurses (Forster et al., 2018: 43). From this partial portrait, we can quickly see substantial inequalities and disparities within the European Union, prevalently along the centre-periphery divide. Among the measures included in European Semester, the Country-Specific Recommendations are built to harmonise and monitor Member States performances in defined policy fields - that could be considered as a 'powerful soft law' instrument (Guy, 2020; Azzopardi-Muscat et al., 2015) able to set standards and benchmarks. The CSRs assumed a peculiar role after the sovereign debt crisis, monitoring commonly agreed budget policies with measures mainly addressed to social matters, growth and investments, always considering public budget contingencies. They represented an operational tool for the European Semester itself. The CSRs have been implemented extensively in health chapters with particular regard to set common standards in critical areas of health policy. As widely 
demonstrated, such measures contributed to shaping national health policy, having particular regard towards cost-effectiveness (Azzopardi-Muscat et al., 2015). That has happened despite the is little room in art. 168 to act in this regard. Such advancements have been possible thanks to the budget and market implications that in every matter of EU Affairs contributed to enhancing integration.

The CSRs demonstrated how integration could proceed in unexpected ways to reach some common objectives. Nonetheless, the overall EU health policy is far from fully reached, and the CSRs in the health field often resulted in expenditure cuts, creating imbalances among the Member States, especially in the social arena (Brooks et al., 2021; Lau et al., 2014; Forster et al., 2018). Another example of the incompleteness of EU health policy is the action in times of crisis. The European Union established several institutions to react in case of emergency: the Health Security Committee (HSC), formalised in 2013, but acts as an informal body since 2001. His action could facilitate EU Member States to promote good practices and ensure national responses to serious transnational menaces (Decision 1082/2013/EU). After a long resistance by the member states, the European Center of Disease Control and Prevention has been created within the EU framework. The ECDC should give the Member States all needed information to counter possible transnational diseases (Greer, 2012b; Deruelle, 2016). The EU also prepared joint coordination of the Civil Protection Center to intervene when a Member State faces a severe disaster or natural calamity. Established in 2001 and institutionalised in 2019, such a system was active within the EU polity and abroad, active mainly in residual circumstances, relying predominantly on voluntary cooperation among the Member States. The overall framework under the dramatic contingency of the Covid-19 pandemic poses some structural questions to public health in the European Union. The Member States have always been jealous of their sovereignty in some key policy fields. Many of them, like health, is profoundly linked to personal and public safety.

The pre-existing differences within the European Union and the Covid-19 pandemic need to be both considered the primary origin of the outcome in health-related outcomes and the economic consequences of the pandemic. The persisting call by the Member States to advocate primary duties in healthcare contributed to preventing effective coordination among the EU Member States in a dramatic contingency like the Covid-19 crisis. In the earliest time of the emergency, indeed, the EU struggled to find a typical posture both on health-related and economic consequences of the pandemic (Ceron et al., 2020). The persisting divergences inherited from previous Sovereign debt and Greek crises created misperceptions, leading to an under-evaluation of the phenomenon. (Ceron. et al., 2020). Such a situation contributed to creating harsh reactions in early affected countries (Palermo, 2020), fuelling the idea that the European Union could not intervene rapidly and effectively to support the Member States in need. Such posture exacerbated differences between the centre and periphery within the European Union and the Member States.

\section{Covid-19: (limited) health coordination in the EU}

The earliest phase of the pandemic was managed mainly by Nation-States traditionally prone to maintain their prerogatives in health policy. Nonetheless, the Covid-19 outbreak hit as all pandemic or large epidemic phenomena in the past, it disrupted normal societal mechanisms, generating pervasive outcomes everywhere in daily life. A pandemic is not just a healthcare problem, is a complex phenomenon starting from health hitting our sociality, the economy, implying some temporary or rather than permanent changes - e.g. the organisation of labour, gender-related impact, inequalities by role, growing of remote working; distance-learning (Shafer et al., 2020; Barbieri et al., 2020; Souza et al., 2021; Clancy, 2020)

Indeed, the health sector has been targeted by an unexpected emergency: none of the previous modelling or exercise prepared medical staff for the impact of the pandemic. The daily medical practice 
has been disrupted and different levels of preparedness in the EU Member States made the situation dramatic for patients and the medical personnel (Herros et al., 2020). Thus, coordination emerged as a primary need, particularly felt in most affected member States during the first wave of the Pandemic. Lack of solidarity has been considered, as we mentioned earlier also, a weakness of the European Union (Palermo, 2020; Ceron et al., 2020)

The National governments, in most of the case, had just Non-Pharmaceutical interventions (NPIs) during the first and the second wave to try to slow the propagations of outbreaks in the continent. Thus, the NPIs (e.g. lockdowns, shutdowns, limitation of crowdy events, social distancing) have been the measures to contain the pandemic in every European Member State even if the severity of the phenomenon was very different from region to region. Those measures demonstrated to have heterogeneous effects within the European Union confirming its positive outcomes in countries where the pandemic hit severely and keeping the situation under control where outbreaks never reached the "breaking point" (Ceron et al., 2021). Despite some discussion about the overall results of the NPIs, their positive impact on pandemic control was widely demonstrated (Correia et al., 2020).

The effects of the pandemic both on health-related matters and the economy called for common action. The EU started to promote a solution to put in practice effective coordination against the Covid-19 diffusion, contributing, together with the Member States, to give a path towards the desired "come back to normality" to citizens and economic actors. The EU, calling its joint procurement prerogative, was able to deal, on behalf of the Union, contracts with pharmaceutical producers, avoiding any other disruptions of the internal cohesion and the common market itself. Another policy promoted by the European Union was the Green-Passport, a safety certificate issued by national authorities or directly by eHealth Portal, after the completed vaccine cycle, be recovered from Covid-19 or after a negative PCR test (European Commission, 2021a). Such measures could ease cross-country travel within the EU promoting loosening of restrictions among the Member States. Nevertheless, the multiple panoplies of national regulations, different sanitary recommendations reduced the scope of the measure. In any case, the need for the Green-Passport shows how essential elements of EU integration require health coordination especially in a dramatic phase like the Covid-19 pandemic.

Therefore, aware of the enduring necessity to ensure supranational coordination and about perduring limits of the Lisbon Treaty, the Member States and the supranational Institutions have been always aware of national action weaknesses and the limits of European action in this regard. The cooperation is devoted, first of all, to guarantee a minimum coordination organising PPE and other medical equipment but also, during the first waves of the pandemic, to organise research and development (and later commercialisation) of the vaccine against SARS-COV-2. Another main issue is guarantee cohesion of the internal market re-establishing free movement liberties, after national initiatives aimed to limit the export of medical equipment and other restrictions in free movement of people, goods and services which proved to compromise Schengen acquis (Greer et al., 2021).

The Covid-19 outbreak forced the Europeans to rethink the impact of the EU health policy. Far to be accomplished (Sorensen et al., 2013), a reflection should be done on the role of common agencies with health-related mandates. Among them, the European Center for Disease Prevention and Control has the role to oversee epidemiological surveillance providing related information and findings to Institutions and the Member States in this field. Such Agency, after a complicated long gestation, was born in 2004 after the sanitary crisis created by SARS, finally pushed the Europeans to constitute it (Greer, 2012b; Deruelle, 2016). The ECDC, despite its ambitions, suffered some constitutive limits: considering the reluctance, by the member states, to assign at the European level any substantial authority over health regulation policies. Therefore, formal powers have been assigned to the newborn agency which remains a hub for information, data sharing and research without a substantial active role (Deruelle \& Engeli, 2021). That is an issue common to several EU agencies created with an ambitious burden but without any effective powers and lacking capital and Human Resources to fully respect its constitutive aims 
(Rittberger \& Wonka, 2011; Egeberg \& Trondal, 2011; Wonka \& Rittberger, 2010). Such framework, limited the outcome of the agency and its overall weight within EU Health Policy, even if, during the pandemic, the agency managed. For that reason, the ECDC never reached, in recent times, the same prestige as its US counterpart (Greer, 2012b). During the Pandemic, the ECDC has been the target for many critical opinions: it has been criticised for not being sufficiently effective and funded, remembering what surveillance implies in a coordinated polity. It is true, in any case, that the American counterpart could benefit from more economic resources and human capital. It is, actually, not comparable with the ECDC (Jordana and Triviño-Salazar, 2020).

Among the other NPIs, closure of borders and travel restrictions have been applied within the European Union since the very beginning of the pandemic, following the example of what happened in China. There is no concordant opinion in scholarship about its role in contributing to stopping (or control) the pandemic (Chinazzi et al., 2020; Linka et al., 2020). Some scholars warn about the overall effects of such policies: despite they could be useful during pandemic peaks, such policies had profound political implications and could generate undesired outcomes (Seyfi et al., 2020). Some others punctually demonstrated that free movement is not fully resilient to crisis; moreover, even if foreseen by the Treaty in case of epidemiological emergency, border closures could constitute a danger for one of the EU constitutive freedom risking to increase the nationalist discourse (Opiłowska, 2021; Bieber, 2020). Remembering, anyway, that travel limitations have been frequent in such times and, especially, those are previewed in time of epidemiological emergency, it is, on the other hand, undeniable that the Schengen liberties have been shrunk and the European Commission was not late recommending to the Member States (June 2020) to plan a coordinated reopening of frontiers (European Commission, 2020a).

Such risk has been considered by the European institutions: the cohesion and the integrity of the Custom Union should be protected and, at the same time, the EU (together with the Member States) should govern the transition towards the end of the pandemic with some active instruments able to push free movement assuring the safety of citizens. The European Green Passport, presented by the

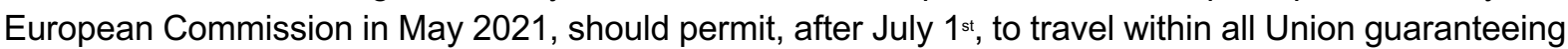
effective travel safety with a negative PCR test, the proof of recovery from Covid-19 or, completed vaccination (European Commission, 2021x). Nevertheless, the Member States implemented different rules to allow free travelling within the EU, they have different health-related measures (e.g. different regulations on PCR tests; different norms about accepted vaccines; etc.) (European Commission, 2021). It is too early, right now, to fully evaluate the outcomes of such a policy, in particular, it will be too early to evaluate the universality of the measure. According to some Member States, such a regulation arrived with a substantial delay than expected European Commission, 2021). The global context in this matter is fuelled by a global rush to find effective vaccines against Covid-19, with the resurgence of vaccine nationalism phenomena (Bollyky \& Bown, 2020; Santos Rutschman, 2020). The major global powers are competing on a global scale to prevail. The objectives are manifold: first, control the pandemic and create a condition to large immunisation, could easily foster economic recovery; second, the vaccine is a political instrument to manage influence and gain credit from other international actors.

To counteract the pandemic, the EU launched an extensive campaign on Covid-19 development. The EU, strong of the support of the Member States (able to designate 2.7 bln EUR), following the joint procurement powers (Directive 2014/24/EU; Decision 1082/2013/EU). Such a decision gave the European Union the chance to avoid any other disruptive competition on price by a single Member State, preserving the integrity of the Custom Market and fostering the European powers on healthrelated market chapters. The joint procurement procedure was already used in the 2010s during the emergency of H1N1 influenza (Greer \& de Ruijter, 2020). Nevertheless, the late approval by the EMA - implementing a brand-new "roll-out" approval mechanism - (European Medicine Agency 2020) together with issues related to export to third countries and difficulties of the suppliers determined a 
delay in European Vaccine Campaign in early 2021 (Torjesen, 2021; Herszenhorn and Vela 2020). In early 2021, the Italian Government, aware of export practices by the suppliers and the critical situation faced by its own national campaign, decided to block export to third countries for all doses produced in Italy (Borrillo, 2021; Herszenhorn \& Vela, 2020). Nowadays, even if Europe seems to have capitalised on its own mistakes and the vaccination campaign seems to be on the right path (De Maio, 2021), we could not forget the impact of the first months. we could not be satisfied with market-related measures. The issues verified with AstraZeneca, the difficulty in early doses supplies due to late rollout and supply to third countries impacted unfairly to the Campaign and, even the initial hurdles seem to be overcome, it is necessary to put in place stronger measures to avoid any disruption in the supply chain that could potentially undermine the scope of the joint procurement (Greer \& de Ruijter, 2020).

As we had a chance to see in such a section, controlling the pandemic, NPIs and vaccination constituted relevant transnational implications going beyond the possibility of travel and exchange of goods. The consequences of the pandemic have surpassed national borders, meanwhile the preparedness of Member States, their pre-existing conditions may have shaped government choices in Covid-19 management and pandemic outcomes. The overview of EU indirect contribution in the health arena through budgetary policies and austerity, as well as direct competencies - or lack thereof - shows problematic dynamics of worsening inequalities without any common tool for mitigation. While unprecedented efforts are underway as a result of the crisis both in the economic and health arenas, the question remains on one side of how such a context fostered fragmented heterogeneous national success in crisis management and how the extent of the problematic divide compare to recent progress in the wake of Covid-19 and reform proposals such as the Health Union.

\section{Pandemic preparedness, responses and outcomes in the Member States}

Many analyses of the geography and consequences of the pandemic have looked at factors explaining heterogeneity in the scale of the cross-country tragedy. Generally, the approach is that of taking a narrow focus on specific outcomes such as cases or mortality in uncovering linkages with country characteristics or policy decisions. Such approaches are outside of the scope of this work in the ambition to derive causal linkages across specific input and outcomes. At the same time, they generally differ by taking a narrow focus on the dependent variable through which to compare the pandemic, defining success - for example - in terms of limiting spread, the mortality rate or the economic cost. Exceptions (e.g. Ceron et al., 2021) have considered the multiple dimensions of the pandemic across the outbreak, containment effort and fiscal support, uncovering through a cluster analysis the geographical divide in the Union in policy responses to the crisis. From a similar perspective, our descriptive comparative analysis considers the pandemic in its multitude of facets, policy decisions and outcomes, while mapping them as well to the cross-country context - especially in the health arena. In this regard, looking at the legacy of the past crisis and the austerity policies to follow, has already indicated heterogeneous preparedness across the Member States. The periphery - hit first by Covid-19 - started for a condition of higher fragility in terms of its potential health interventions.

From such a perspective in line with the research questions and argument of the paper the core point of the analysis is to show the geographical dimensions and continuities between the pre-existing condition of health preparedness stomped by austerity, restrictive Covid-19 containment policy choices and problematic outcomes both in economic and human terms. The implication of the latter is not just a matter of inequalities per se: in the context of a transboundary crisis with high externalities and crossborder interdependencies, the spillovers from less successful performance - in its broader meaning indicated above - comes at a cost which exceeds that of the single Member State. That is to say that while the cost of the Covid-19 emergency is unevenly distributed across countries exiting from the heat 
of the pandemic crisis toward the reconstruction within the EU is a matter of common interest, especially if the existing level of integration is to be maintained.

At the operational level the comparative analysis proceeds by generating scoreboards for the EU27 across three - themselves multifaceted - dimensions: that of background, outbreak and outcomes characteristics. In doing so, we employ several datasets, starting from one of mainstreamed use in cross-country comparisons of pandemic management: the Oxford Covid Government Response Tracker - OxCGRT (Hale et al., 2021). From OxCGRT, we derive and aggregate over 2020 variables accounting policy responses to the outbreak in the Member States. The datasets contain several indicators of individual measures of restriction and containment. Restrictions include measures ranging from lockdowns, school and workplace closures to ones with a less broad impact on life activities such as international and internal travel restrictions or limitations on public gatherings. On the containment side, measures range from the key variables of testing and tracing to masking mandates and public information campaigns. In addition, aggregate indices are generated in the OxCGRT on restriction alone with the Stringency Index or for the more inclusive Containment Index. In addition, cumulative cases and deaths per million inhabitants - allowing for proportional cross-country comparisons - are sourced from the Oxford Our World in Data dataset (), which builds on the John Hopkins University CSSE Covid19 data tracker. The dataset also contains background data on factors potentially connected with spread and mortality, such as population density, demography and hospital beds. In addition, Eurostat data allows tracking health expenditures over time (), as well as economic performance in 2020 (). Finally, the European Commission Autumn Forecasts provide data on the fiscal stimulus enacted by the Member States in response to the pandemic, complemented by a similar effort from Bruegel () for the sole missing value of Spain.

Based on such data, the generation of the scoreboards follows the same principles. For each indicator, its range is split into thirds reflecting each mark following street-light colouring. The choice of the scale depends on what the indicator measures rather than homogeneously marking the top and bottom values. That is to say that when high values indicate worse input or outcomes for the pandemic, they are graded with the red colour (e.g. cases, population density, share of over 70 , mortality). Conversely, variables that contribute to pandemic preparedness or positive outcomes (e.g. health spending, fiscal stimulus, GDP change) follow the opposite colouring: green represents high values while red is low. There is one exception to such an approach for ease of interpretation: to facilitate a parallel with "red" or "green" outbreaks similarly restrictions and containment measures are ranked red when high and green with mild. As a result, visually it is more straightforward to spot the mismatch between severe outbreaks and loose policy responses or conversely stringent measures in the absence of a high case and death toll.

For what concerns the background situation in the Member States, the scoreboard in table one considers selected fragility factors. While displaying population density and share of the elderly population, often claimed as important drivers of the tragedy of the pandemic, the core of the scoreboard are devoted to the central claim of the article - that is to say health preparedness. Section two already made a compelling case for the contribution of austerity to deepen inequalities and curb preparedness in the health domain, especially in Southern Europe. Table 1 confirms such patterns. In terms of the "output" of austerity in the health arena, the scoreboard displays hospital beds per thousand ahead of the pandemic. Health spending dynamics follow, as anticipated in section two both in terms of GDP per capita and share of the budget, considering the evolution over time from the pre-Great Recession levels, during the crisis and end-points ahead of the pandemic. While the geographical context is more mixed for the other variables, health spending trends are especially damaging for the periphery. Indeed, in terms of hospital beds along with countries heavily hit by austerity (Cyprus, Ireland, Italy, Portugal and Spain), the bottom end of the spectrum houses two core countries as well (Netherlands and Sweden). At the same time, the Eastern bloc is better endowed than their ranking in terms of health spending would suggest. Nevertheless, some of the countries with mid-to-high beds in the South and East of 
Europe - even when not overwhelmed in terms of size of the outbreak - display high mortality rates (Greece, Hungary, Bulgaria). Conversely, the Netherlands scores fairly low on such an outcome. hospital beds alone may hence not fully reflect health preparedness.

Shifting the focus to health spending trends, the broad geographical distinction singles out the bulk of the Central and Eastern bloc, together with Croatia and Cyprus as those with the lowest spending overall. Trends are mixed, with some improvements over time (e.g. Bulgaria, Croatia, Romania) and others worsening their position (e.g. Cyprus, Latvia). The latter trend is generally through for the periphery, regardless of their relative position in terms of spending before the crisis. Greece, for example, experiences a decrease in spending both in terms of GDP and as a share of the budget, moving downward from the top third to the middle range in terms of GDP (with the most sizable drop overall of 1.5 points) and the red area in terms of share by 2018. The same downward shift - albeit contained to "only" 1 point of GDP - occurs for Portugal moving down from Green to yellow. Spain also experienced a ranking demotion in terms of its share of the budget devoted to health, shifting to the top third to middling. Another country heavily impacted by austerity - Ireland - experiences the sharpest decrease in spending, relinquishing its position in the top third range in terms of GDP by 2018. The key message is that in terms of fragility factors an imperfect simplification indicates the Eastern and Southern Member States as less prepared to handle the crisis, with austerity as a potentially strong contributor of such patterns in the periphery.

Table 1 - Scoreboard of selected fragility factors heading into the Covid-19 pandemic

\begin{tabular}{|c|c|c|c|c|c|c|c|c|c|c|c|c|c|c|c|c|c|c|c|c|}
\hline & & 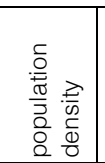 & & $\begin{array}{l}0 \\
\\
\frac{1}{0} \\
0 \\
0 \\
\frac{1}{\sigma} \\
\frac{\pi}{\omega} \\
\end{array}$ & \begin{tabular}{|l|}
0 \\
0 \\
0 \\
0 \\
$\frac{\pi}{0}$ \\
00 \\
00 \\
0 \\
0 \\
\end{tabular} & 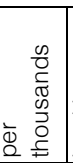 & 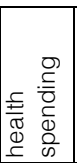 & 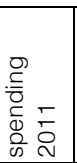 & 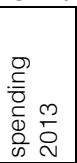 & 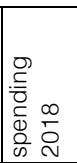 & & $\begin{array}{l}\tau \\
\overline{1} \\
\infty \\
0 \\
0 \\
\frac{1}{0} \\
\frac{1}{0}\end{array}$ & 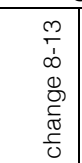 & & $\begin{array}{l}\infty \\
\overline{1} \\
\infty \\
0 \\
0 \\
\frac{0}{\sigma} \\
\frac{c}{0}\end{array}$ & 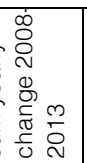 & 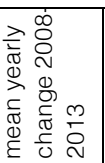 & 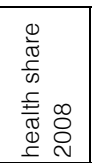 & 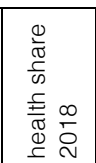 & 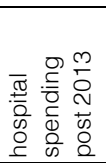 \\
\hline Aust & 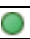 & 106.75 & 0 & 13.75 & 0 & 7.37 & 07.5 & 07.7 & 07.8 & 8.2 & 0 & 0.2 & $\begin{array}{ll}0 & 0.3 \\
\end{array}$ & 0 & 0.7 & $\begin{array}{ll}0 & 0.4 \\
\end{array}$ & 0.07 & 0.15 & 0.17 & 4.62 \\
\hline elg & 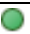 & 375.56 & 0 & 12.85 & 0 & 5.64 & 7.3 & ( 7.7 & 8.0 & 7.6 & 2 & 0.4 & $\begin{array}{|ll|} & 0.7 \\
\end{array}$ & 0 & 0.3 & $\begin{array}{|ll|} & 1.2 \\
\end{array}$ & 0.20 & 0.14 & 0.15 & 3.72 \\
\hline Bulg & O & 65.18 & 0 & 3.27 & 0 & 7.45 & 4.4 & 4.2 & 4.5 & 5.0 & $\mathrm{O}$ & -0.2 & 00.1 & 0 & 0.6 & \begin{tabular}{ll|} 
& 0.5 \\
\end{tabular} & .08 & 12 & 14 & 62 \\
\hline $\mathrm{ro}$ & 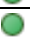 & 73.73 & 0 & 13.05 & 0 & 5.54 & 3.7 & 4.3 & 4.5 & 6.6 & 0 & 0.6 & 0.8 & 0 & 2.9 & $\begin{array}{|ll|} & 0.6 \\
\end{array}$ & 0.10 & 0.08 & 0.14 & 2.94 \\
\hline Cypr & 0 & 127.66 & 0 & 8.56 & 0 & 3.40 & \begin{tabular}{|l|} 
\\
\end{tabular} & 3.1 & 3.1 & 2.7 & O & 0.4 & $\begin{array}{|ll|} & 0.4 \\
\end{array}$ & 0 & 0.0 & \begin{tabular}{ll|} 
& 0.5 \\
\end{tabular} & 0.08 & 0.07 & 0.06 & .84 \\
\hline$z e$ & ) & 137.18 & 0 & .58 & 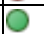 & 6.63 & 6.9 & ( 7.7 & 7.6 & 7.6 & 0 & 0.8 & 0.7 & 0 & 0.7 & $\begin{array}{|ll|} & 0.8 \\
\end{array}$ & .13 & 0.17 & 0.19 & 38 \\
\hline Den & 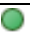 & 136.52 & 0 & 12.33 & 0 & 2.50 & 7.9 & 8.4 & 8.5 & 8.3 & D & 0.5 & 00.6 & 0 & 0.4 & $\begin{array}{|ll|} & 0.8 \\
\end{array}$ & 0.13 & 0.16 & 0.16 & .02 \\
\hline sto & 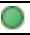 & 31.03 & 0 & 3.49 & 0 & 4.69 & 5.1 & 4.9 & 5.0 & 5.1 & 0 & -0.2 & $0-0.1$ & 0 & 0.0 & $\begin{array}{|ll|} & 0.7 \\
\end{array}$ & 0.12 & 0.13 & 0.13 & .74 \\
\hline inl & 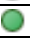 & 18.14 & 0 & .26 & 0 & 3.28 & 06.7 & 7.4 & 7.8 & 7.0 & O & 0.7 & \begin{tabular}{ll|} 
& 1.1 \\
\end{tabular} & 0 & 0.3 & $\begin{array}{|ll|} & 1.3 \\
\end{array}$ & 0.22 & 0.14 & 0.13 & .12 \\
\hline Fran & D & 122.58 & 0 & 13.08 & 0 & 5.98 & 7.4 & 7.9 & 8.1 & 8.1 & P & 0.5 & $\begin{array}{lll} & 0.7 \\
\end{array}$ & 0 & 0.7 & $\begin{array}{|ll|}0 & 0.6 \\
\end{array}$ & 0.10 & 0.14 & 0.14 & 3.48 \\
\hline er & 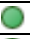 & 237.02 & 0 & 15.96 & 0 & 8.00 & 06.5 & 6.8 & 7.1 & 7.2 & 0 & 0.3 & $\begin{array}{|cc|} & 0.6 \\
\end{array}$ & 0 & 0.7 & $\begin{array}{|ll|}0 & 0.7 \\
\end{array}$ & $\begin{array}{ll}0 & 0.12 \\
\end{array}$ & 0.15 & 0.16 & .80 \\
\hline Gre & 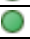 & 83.48 & 0 & 14.52 & 0 & 4.21 & 06.5 & 6.5 & 5.2 & 5.0 & 0 & 0.0 & $0-1.3$ & 0 & -1.5 & $0-0.8$ & -0.13 & 0.13 & 0.11 & 3.00 \\
\hline un & 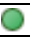 & 108.04 & 0 & 11.98 & 0 & 7.02 & 4.9 & 5.1 & 5.0 & 4.7 & P & 0.2 & 0.1 & 0 & -0.2 & \begin{tabular}{ll|} 
& 0.1 \\
\end{tabular} & 0.02 & 0.10 & 0.10 & 12 \\
\hline Irela & 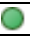 & 37 & 0 & 8.68 & 0 & 2.96 & 6.9 & 07.6 & 07.2 & 5.0 & P & 0.7 & $\begin{array}{ll} & 0.3 \\
\end{array}$ & 0 & -1.9 & $\begin{array}{|ll|} & 1.0 \\
\end{array}$ & $\begin{array}{ll} & 0.17 \\
\end{array}$ & 17 & 0 & 08 \\
\hline Italy & 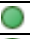 & 205.86 & 0 & 16.24 & 0 & 3.18 & 07.0 & 7.1 & 7.1 & 6.8 & P & 0.1 & $\begin{array}{|ll|} & 0.1 \\
\end{array}$ & 0. & -0.2 & $\begin{array}{|ll|}0 & 0.4 \\
\end{array}$ & 0.07 & 0.15 & 0.14 & 2.90 \\
\hline Lat & 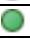 & 31.21 & 0 & 14.14 & 0 & 5.57 & \begin{tabular}{|l|} 
\\
\end{tabular} & O 4.1 & 3.7 & 4.0 & 5 & -0.2 & - -0.6 & 0 & -0.3 & $0-0.3$ & -0.05 & 0.11 & 0.10 & O \\
\hline \begin{tabular}{|l|} 
Lithi \\
\end{tabular} & 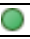 & 45.14 & 0 & 13.78 & 0 & 6.56 & 5.6 & 6.7 & 5.6 & 5.9 & P & 1.1 & 00.0 & 0 & 0.3 & $\begin{array}{|ll|} & 0.4 \\
\end{array}$ & 0.07 & 0.15 & 0.17 & .14 \\
\hline Luxe & D & 231.45 & 0 & 9.84 & 0 & 4.51 & . 4.4 & . 4.7 & 5.2 & 4.7 & 0 & 0.3 & 0.8 & 0 & 0.3 & $\begin{array}{|ll|} & 0.9 \\
\end{array}$ & 0.15 & 0.11 & 0.11 & .10 \\
\hline lalts & & 1454.04 & 0 & 11.32 & 0 & 4.49 & 5.3 & 5.4 & 5.7 & 5.3 & 0 & 0.1 & 0.4 & 0 & 0.0 & $\begin{array}{|ll|} & 0.2 \\
\end{array}$ & 0.03 & 0.12 & 0.15 & O \\
\hline Neth & & 508.54 & 0 & 11.88 & 0 & 3.32 & 6.6 & 07.9 & 8.1 & 7.6 & O & 1.3 & $\begin{array}{ll}0 & 1.5 \\
\end{array}$ & 0 & 1.0 & $\begin{array}{|ll|} & 1.4 \\
\end{array}$ & 0.23 & 0.15 & 0.18 & 3.58 \\
\hline Poland & & 124.03 & 0 & 10.20 & 0 & 6.62 & 5.0 & . 4.7 & 4.6 & 4.8 & P & -0.3 & $0-0.4$ & 0. & -0.2 & $\begin{array}{|ll|} & 0.1 \\
\end{array}$ & $0 \quad 0.02$ & 0.11 & 0.12 & 2.86 \\
\hline Portt & & 112.37 & 0 & 14.92 & 0 & 3.39 & 07.3 & P 7.0 & 6.5 & 6.3 & 0 & -0.3 & $0-0.8$ & 0 & -1.0 & $0-0.6$ & 0.0 .10 & 0.16 & 0.15 & 3.38 \\
\hline Rom & & 85.13 & 0 & 11.69 & 0 & 6.89 & 3.6 & O 4.2 & 4.0 & 4.7 & D & 0.6 & 0.4 & 0 & 1.1 & $\begin{array}{|ll|} & 0.4 \\
\end{array}$ & 0.07 & 0.10 & 0.13 & 2.28 \\
\hline lov & 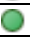 & 113.13 & 0 & 9.17 & 0 & 5.82 & 6.8 & O 7.0 & O 7.0 & 7.3 & P & 0.2 & $\begin{array}{ll} & 0.2 \\
\end{array}$ & 0 & 0.5 & $\begin{array}{|ll|} & 0.8 \\
\end{array}$ & 0.13 & 0.18 & 0.18 & 3.18 \\
\hline Sloveni & & 102.62 & 0 & 12.93 & 0 & 4.50 & 06.2 & P 7.0 & 6.8 & 6.6 & 0 & 0.8 & $\begin{array}{|ll|} & 0.6 \\
\end{array}$ & 0 & 0.4 & $\begin{array}{|ll|} & 0.9 \\
\end{array}$ & 0.15 & 0.14 & 0.15 & 3.06 \\
\hline Spain & & 93.11 & 0 & 13.80 & 0 & 2.97 & 6.1 & 6.5 & 6.2 & 6.0 & J & 0.4 & \begin{tabular}{ll|} 
& 0.1 \\
\end{tabular} & 0 & -0.1 & \begin{tabular}{ll|} 
& 0.5 \\
\end{tabular} & 0.08 & 0.15 & 0.14 & 0.00 \\
\hline veden & & 24.72 & 0 & 13.43 & 0 & 2.22 & 6.6 & 6.7 & 6.9 & 7.0 & 0 & 0.1 & $\begin{array}{ll} & 0.3 \\
\end{array}$ & 0 & 0.4 & \begin{tabular}{ll|} 
& 0.5 \\
\end{tabular} & 0.08 & 0.13 & 0.14 & 2.54 \\
\hline
\end{tabular}

Coming to the pandemic, the message of heterogeneity displayed by Table 1 finds continuation in the context of the Covid-19 crisis. Countries differ in terms of outbreak severity, overall response stringency as well as choice across specific policy measures. The linkages across the three dimensions are moreover far from univocal: countries heavily hit by the pandemic display varied responses both in overall strength and their composition which is also the case for the Member States with more limited outbreaks which at times are featured among those with heavy restrictions. Such differences also extend to policy choices as indicated by the differences between the stringency and health index, falling into different groupings for five countries - Belgium and Spain with weaker containment than stringency 
(indicating more stringency in health-related measures than restrictions) while the opposite is the case for Croatia, Latvia and Malta. Beyond the differences across the two aggregate indices, it is notable that countries do not necessarily align in their ranking across pandemic severity and stringency of restrictions and/or containment efforts. Some display at least for one of the indices a lower grade than those of the outbreak (e.g. Belgium, Croatia, the Czech Republic, Lithuania, Luxembourg, Slovenia) while others - among which sit all Southern Member States - display the opposite pattern (Cyprus, Denmark, France, Germany, Greece, Ireland, Italy, Malta, Portugal, Spain): higher grade containment responses than their outbreaks. Such patterns in the periphery do not only include heavily hit countries such as Italy, Spain and Portugal, but also those with limited contagions such as Cyprus, Greece and Malta. For them the gap between pandemic and response ranking is at the two ends of the spectrum, scoring green for the outbreak and red for restrictions. That is also the case for Ireland, another country having experienced among the worst austerity budget diets.

Moving to the individual variables, we display those with the broadest relevance and societal implications (e.g. school closures and lockdowns), heterogeneity across the Member States (which is not the case, for example, for public information campaigns) and with arguably some level of a policy decision not linked only to rationing (e.g. excluding mask mandates, especially in the first months of the pandemic). Again the alignment is limited not only with the outbreak but also with overall indices denoting different policy choices to obtain a similar level of restrictions across the Member States. All selected individual indicators display some level of mismatch. While far from perfect complementarity, some level of trade-off does emerge between containment in the health arena - through testing and tracing - and restrictions such as school closures and lockdowns. A country such as Spain, achieving overall among the highest stringency index, had the highest mean over 2020 for the lockdown indicator, which only middling variables in testing and tracing. The opposite is the case for Malta, with the highest level of testing across the EU27 and likewise at the top for tracing, obtaining a "red" containment with a middling level of school closures and a low one for lockdowns. But that need not necessarily be the case as, for example, in Cyprus to a high level of testing and tracing correspond a high lockdown means and a middling one for school closure even in the presence of a "green" outbreak, with the secondlowest level of deaths across the Union. An analysis clustering pandemic management across the Member States (Ceron et al., 2021) has uncovered some general geographical patterns in Covid-19 response models confirmed by the scoreboard: an over-reliance on lockdowns and especially school closures in the South and East of Europe - even when their outbreak severity is on the mild side - while the opposite in terms of testing and tracing. Except for those mostly spared by contagion, Cyprus and Malta, no other Southern Member State achieves a red ranking both for testing and tracing. Conversely, only Malta among them does not display at least one "red" scoring in terms of school closures and lockdowns. In comparing the lockdown and school closure scores (see Figure A1 in the appendix) we see substantial over-reliance on school closures especially in periphery countries such as Italy and several ones in Central and Eastern Europe.

A final dimension concerns the economic response, also far from aligned in ranking both with pandemic severity and stringency of responses. Countries like Estonia, which did not have a severe outbreak nor enacted stringent and costly restrictions, display among the highest levels of the fiscal stimulus relative to their GDP. The same is the case for Lithuania, which albeit a stronger outbreak enacted very limited restrictions but a strong fiscal response. At the opposite end of the spectrum, we have countries such as Ireland and Greece, ranking low for the outbreak, high for restrictions and displaying limited economic support measures, reaching the lowest level overall for Greece. Other countries in the periphery - such as Cyprus, Portugal and Spain, display a less marked but nevertheless substantial gap in the ranking across pandemics, restrictions and fiscal support indicating strong containment responses paralleled with weaker stimulus measures. The comparison between both cases and stringency index and stimulus in Figure A2 and A3 in the appendix further evidence such differences. The overall message one can derive from the scoreboard is heterogeneity in the chosen level of responses for similar outbreak levels, themselves then differing in the chosen policy mix. Some 
of the heavily hit Member States - especially in the South - had tracing and testing policies which suggest less health capacity. Similarly, periphery countries - whose less marked health preparedness was evidenced in Table 1, further reinforced in Figure A4 and A5 in the appendix comparing hospital beds to lockdowns and the stringency index - enacted more draconian restrictions, even when faced with limited and moderate contagion. Such patterns are not driven entirely by the early response, as explored as cross-wave sensitivity in the scoreboard in table A1. Indeed, some countries such as Cyprus and Greece display increasingly higher level of restrictions comparatively to their outbreak severity in during the second wave during which geographical divides in response models hardly disappear. At the same time, stimulus support did not necessarily follow in the same scale as the pervasiveness of costly restrictions in the South of Europe. As a result, inequalities in health preparedness may have translated into a capacity for containment not always up to the challenge for the worst-hit Member States. Given the transnational spillovers and implications in a highly integrated and interdependent context as that of the EU, such patterns pose the question of whether fragmented responses which leave substantial geographical segments behind are not suboptimal for the entirety of the Member States. While not the focus of the analysis, similar imbalances emerge on the economic front, which may further reinforce the divide and the vicious cycle of widening geographical gaps, in turn making convergence also in health preparedness unlikely in the weaker Member States.

Table 2 - Scoreboard of outbreak severity and policy response measures

\begin{tabular}{|c|c|c|c|c|c|c|c|c|c|c|c|c|c|c|c|c|c|}
\hline 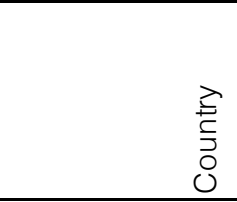 & & 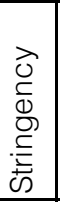 & & 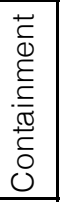 & & $\begin{array}{l}0 \\
0 \\
0 \\
\frac{0}{0} \\
0 \\
\infty\end{array}$ & & \begin{tabular}{l}
0 \\
\multirow{2}{3}{} \\
0 \\
0 \\
$\frac{0}{0}$ \\
0 \\
0 \\
\end{tabular} & & 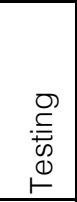 & & 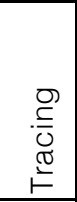 & & 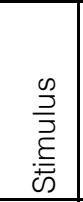 & $\begin{array}{l}\infty \\
0 \\
\infty \\
\widetilde{D} \\
0\end{array}$ & & 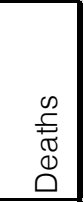 \\
\hline Austria & $\mathrm{O}$ & 56 & 0 & 57 & O & 1.43 & 0 & 0.86 & O & 2.16 & $\mathrm{O}$ & 1.91 & 0 & 6.25 & O40062 & 0 & 691 \\
\hline Belgium & O & 60 & O & 58 & O & 1.37 & $\mathrm{O}$ & 1.19 & O & 1.79 & O & 1.78 & O & 3.00 & O 55782 & O & 1685 \\
\hline Bulgaria & O & 48 & O & 43 & O & 2.07 & O & 0.36 & O & 0.98 & 0 & 1.61 & O & 2.00 & 29110 & 0 & 1090 \\
\hline Croatia & $\mathrm{O}$ & 49 & 0 & 54 & $\overline{0}$ & 1.79 & $\mathrm{O}$ & 0.71 & O & 2.27 & $\mathrm{O}$ & 2.00 & O & 3.00 & 51358 & 0 & 955 \\
\hline Cyprus & O & 64 & 0 & 62 & O & 1.97 & O & 1.33 & O & 2.66 & 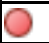 & 1.81 & 0 & 4.00 & - 25139 & O & 136 \\
\hline Czech Republic & $\mathrm{O}$ & 52 & 0 & 54 & O & 1.83 & O & 0.77 & 0 & 1.89 & $\mathrm{O}$ & 2.00 & 0 & 4.00 & 67108 & 0 & 1081 \\
\hline Denmark & 0 & 54 & 0 & 50 & $\overline{0}$ & 1.58 & 0 & 0.92 & $\mathrm{O}$ & 2.57 & 0 & 1.00 & 0 & 4.50 & 28334 & $\mathrm{O}$ & 224 \\
\hline Estonia & $\mathrm{O}$ & 44 & 0 & 40 & 0 & 1.46 & 0 & 0.33 & 0 & 1.84 & 0 & 0.44 & 0 & 6.00 & 21100 & 0 & 173 \\
\hline Finland & 0 & 44 & 0 & 41 & 0 & 1.23 & 0 & 0.33 & 0 & 1.58 & 0 & 1.00 & 0 & 2.60 & $\begin{array}{|ll|}0 & 6517 \\
\end{array}$ & 0 & 101 \\
\hline France & 0 & 64 & 0 & 62 & 0 & 1.86 & 0 & 0.99 & 0 & 2.34 & 0 & 1.77 & 0 & 3.00 & 39292 & 0 & 950 \\
\hline Germany & $\mathrm{O}$ & 61 & 0 & 59 & 0 & 1.83 & 0 & 0.68 & 0 & 2.28 & 0 & 1.71 & 0 & 4.70 & - 21013 & $\mathrm{O}$ & 403 \\
\hline Greece & 0 & 64 & 0 & 62 & 0 & 1.84 & 0 & 1.33 & 0 & 2.31 & 0 & 1.41 & 0 & 1.10 & - 13321 & 0 & 464 \\
\hline Hungary & 0 & 58 & 0 & 53 & 0 & 1.96 & $\mathrm{O}$ & 1.14 & $\mathrm{O}$ & 1.26 & $\mathrm{O}$ & 1.87 & 0 & 3.00 & 33385 & 0 & 987 \\
\hline Ireland & 0 & 66 & 0 & 61 & 0 & 2.17 & 0 & 1.15 & 0 & 1.75 & 0 & 1.69 & 0 & 2.50 & 18587 & 0 & 453 \\
\hline Italy & 0 & 68 & 0 & 67 & 0 & 2.59 & 0 & 1.22 & 0 & 2.00 & 0 & 2.00 & 0 & 5.50 & 34851 & 0 & 1227 \\
\hline Latvia & $\mathrm{O}$ & 51 & 0 & 51 & $\overline{0}$ & 2.47 & $\mathrm{O}$ & 0.67 & 0 & 2.08 & 0 & 1.37 & 0 & 4.00 & 21686 & $\mathrm{O}$ & 337 \\
\hline Lithuania & $\mathrm{O}$ & 50 & 0 & 48 & 0 & 1.94 & 0 & 0.84 & 0 & 1.91 & 0 & 1.66 & 0 & 6.00 & 52145 & 0 & 660 \\
\hline Luxembourg & O & 52 & 0 & 52 & O & 1.37 & 0 & 1.19 & 0 & 2.57 & 0 & 2.00 & O & 3.10 & \begin{tabular}{|l|} 
\\
\end{tabular} 4148 & 0 & 791 \\
\hline Malta & 0 & 54 & 0 & 58 & 0 & 1.68 & 0 & 0.50 & 0 & 2.89 & 0 & 2.00 & O & 5.75 & 28931 & 0 & 496 \\
\hline Netherlands & O & 59 & 0 & 54 & O & 1.55 & $\mathrm{O}$ & 1.12 & 0 & 1.70 & 0 & 1.63 & O & 6.50 & 447178 & 0 & 673 \\
\hline Poland & $\mathrm{O}$ & 56 & 0 & 51 & 0 & 2.19 & 0 & 0.45 & 0 & 1.63 & 0 & 0.90 & 0 & 5.25 & 34214 & 0 & 754 \\
\hline Portugal & $\mathrm{O}$ & 67 & 0 & 61 & O & 1.82 & 0 & 1.33 & O & 2.79 & 0 & 1.03 & O & 3.00 & 40570 & 0 & 677 \\
\hline Romania & $\mathrm{O}$ & 59 & 0 & 51 & O & 2.44 & 0 & 1.17 & 0 & 1.74 & 0 & 1.12 & O & 1.30 & 32866 & 0 & 820 \\
\hline Slovak Republic & $\mathrm{O}$ & 54 & 0 & 57 & 0 & 2.08 & 0 & 0.79 & 0 & 1.96 & 0 & 2.00 & 0 & 2.20 & 32885 & $\mathrm{O}$ & 392 \\
\hline Slovenia & $\mathrm{O}$ & 60 & 0 & 58 & 0 & 1.86 & $\mathrm{O}$ & 0.68 & 0 & 1.98 & $\mathrm{O}$ & 1.71 & O & 5.20 & O 58757 & $\mathrm{O}$ & 1297 \\
\hline Spain & $\mathrm{O}$ & 66 & 0 & 57 & (1) & 2.08 & $\mathrm{O}$ & 1.46 & 0 & 1.78 & 0 & 1.00 & O & 4.30 & 41242 & 0 & 1087 \\
\hline Sweden & 0 & 57 & 0 & 51 & O & 1.53 & 0 & 0.92 & O & 1.69 & 0 & 1.07 & 0 & 3.00 & 44308 & 0 & 864 \\
\hline
\end{tabular}

Coming to the last scoreboard, a key question concerns heterogeneity of outcomes across the Member States and how they compare to preparedness and pandemic management. Two outcome variables are considered: the economic cost of the pandemic in terms of fall in GDP in 2020 and its 
human cost signalled by the mortality rate. In terms of economic outcomes, the periphery has worse performance. In comparison with the level of stringency, even the periphery country with less severe measures (and essentially spared by the outbreak) - Malta - ends of the bottom with among the highest cost of the pandemic in terms of GDP, with the remaining Southern countries clustered in the bottom right: heavy restrictions and comparatively heaven worse economic outcomes. The comparisons by cases are even less rosy for the periphery: Southern Member States cluster at the extreme bottom in terms of GDP outcome, while at the low end of the spectrum of cases proportional to the population (Cyprus and Malta) or at most middling (Italy, Portugal and Spain). In terms of mortality rate, there is extensive heterogeneity overall. Two countries in the periphery (Greece and Italy) are at the higher end of the spectrum, only topped by Bulgaria. While the only country in the periphery - Cyprus with among the least severe outbreaks - scores in the "green" for mortality rate, substantial heterogeneities emerge, with some at the higher boundaries of the middling group and with the sixth-highest mortality overall (Spain) while others (Malta and Portugal) as among the lowest in the yellow group. Linkages with pandemic responses are also less straightforward: stringent responses do not necessarily spare from such negative outcomes as in the case of Italy and (especially given the limited cases) Greece. Nevertheless, as shown in Figure A8 heterogeneities are substantial at all levels of responses, with the worst relative performance emerging in the Eastern bloc. Overall, the only variable with highly (negative) correlates with the mortality rate is testing policies, those with the lowest values in the indicator (Bulgaria and Hungary) are also those with the worst mortality rates. Also in this dimension, however, extensive differences remain, especially in the middle of the distributions. Looking at the correlations of the prepandemic health variables, hospital beds negatively correlate with restrictions and especially lockdowns, like the change in health spending between 2008 and 2018, which also does for school closures. The indication is that the health context and especially the strength of austerity policies did play a role in tilting the hands of governments toward more draconian restrictions.

Table 3 - Scoreboard of outbreak measures and outcomes 


\begin{tabular}{|c|c|c|c|c|c|c|c|c|c|c|c|c|c|}
\hline 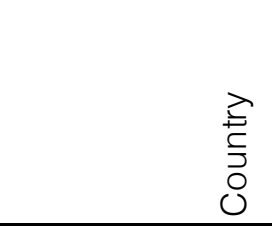 & & 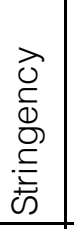 & & 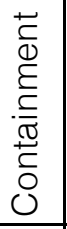 & & $\begin{array}{l}0 \\
\mathbb{1} \\
\infty \\
0 \\
0\end{array}$ & & $\begin{array}{l}\stackrel{\infty}{ \pm} \\
\stackrel{\Phi}{ \pm} \\
\stackrel{D}{D} \\
0\end{array}$ & & $\begin{array}{l}\frac{\infty}{D} \\
\frac{\vec{V}}{\vec{E}} \\
\frac{\vec{\omega}}{\omega} \\
\end{array}$ & & 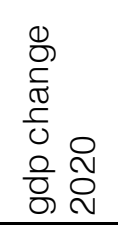 & 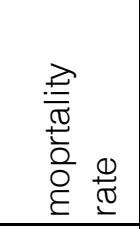 \\
\hline ust & 0 & 56 & 0 & 57 & 0 & 062 & & 691 & 0 & 6.3 & & $-6.0 \%$ & $1.7 \%$ \\
\hline $\mathrm{m}$ & 0 & 60 & 0 & 58 & 0 & & & 1685 & 2 & 3.0 & & & \\
\hline גI & 0 & 48 & 0 & 3 & 0 & & & 1090 & 0 & 2.0 & & $-0.3 \%$ & \\
\hline & 0 & 49 & 0 & 54 & 0 & & P & 955 & 0 & 3.0 & & $8.8 \%$ & 1.9 \\
\hline Сур & 0 & 64 & 0 & 62 & 0 & 39 & & 136 & 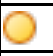 & 4.0 & & $-6.7 \%$ & $0.5^{\circ}$ \\
\hline olic & 0 & 52 & 0 & 54 & 0 & 67 & & 1081 & 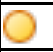 & 4.0 & & $-4.9 \%$ & 1.6 \\
\hline on & 0 & 54 & 0 & 50 & 0 & & & 224 & 5 & 4.5 & & $\%$ & 0 \\
\hline & 0 & 44 & 0 & 0 & 0 & & 0 & 173 & 0 & 6.0 & & $3.7 \%$ & 0.8 \\
\hline & 0 & 44 & 0 & 41 & 0 & 7 & 0 & 101 & 0 & 2.6 & & $-1.3 \%$ & ( 1. \\
\hline ar & 0 & 64 & 0 & 62 & 0 & 39292 & 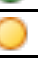 & 950 & 0 & 3.0 & & $-6.3 \%$ & 2.4 \\
\hline er & 0 & 61 & 0 & 59 & 0 & 21013 & $\bar{P}$ & 403 & 2 & 4.7 & & $-3.5 \%$ & .9 \\
\hline Gre & 0 & 64 & 0 & 62 & 0 & & & 464 & 0 & 1.1 & D & $-9.5 \%$ & O 3.5 \\
\hline & 0 & 58 & 0 & 53 & 0 & 85 & 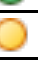 & 987 & 0 & 3.0 & & $-6.8 \%$ & 3.0 \\
\hline elar & 0 & 66 & 0 & 61 & 0 & 18587 & 0 & 453 & 0 & 2.5 & & $1.8 \%$ & 0 \\
\hline aly & 0 & 68 & 0 & 67 & 0 & 51 & 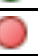 & 1227 & 0 & 5.5 & 0 & $-7.3 \%$ & 3.5 \\
\hline Laty & 0 & 51 & 0 & 51 & 0 & 21686 & $\overline{0}$ & 337 & 0 & 4.0 & 5 & $-3.0 \%$ & 01.6 \\
\hline L & 0 & 50 & 0 & 48 & 0 & 52145 & & 660 & 0 & 6.0 & & $0.2 \%$ & 1.3 \\
\hline & 0 & 52 & 0 & 52 & 0 & & & 791 & 0 & 3.1 & & $-0.5 \%$ & 0 \\
\hline al & 0 & 54 & 0 & 58 & 0 & 31 & $=$ & 496 & 0 & 5.8 & & $-7.6 \%$ & 0 \\
\hline ett & 0 & 59 & 0 & 54 & 0 & 47178 & $\overline{0}$ & 673 & 5 & 6.5 & 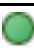 & $-2.0 \%$ & 01.4 \\
\hline Pola & 0 & 56 & 0 & 51 & 0 & 34214 & 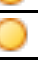 & 754 & 5 & 5.3 & 5 & $-1.9 \%$ & 2.2 \\
\hline Port & 0 & 67 & 0 & 61 & 0 & 40570 & & 677 & 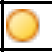 & 3.0 & & $-5.6 \%$ & 17 \\
\hline & 0 & 59 & 0 & 51 & 0 & & & 820 & 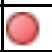 & 1.3 & & $-1.9 \%$ & 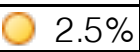 \\
\hline Slov & 0 & 54 & 0 & 57 & 0 & 32885 & 0 & 392 & 5 & 2.2 & & $-2.6 \%$ & 0 \\
\hline Slov & 0 & 60 & 0 & 58 & 0 & 58757 & & 1297 & 5 & 5.2 & & $-5.0 \%$ & 02.2 \\
\hline pai & 0 & 66 & 0 & 57 & 0 & 41242 & & 1087 & 2 & 4.3 & & $-10.4 \%$ & 226 \\
\hline weden & 0 & 57 & 0 & 51 & 0 & 43308 & & 864 & & 3.0 & & $-1.2 \%$ & 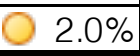 \\
\hline
\end{tabular}

The overall message from the third scoreboard aligns with the previous ones: "success" in managing the pandemic, measured both in the health and economic dimensions, varies substantially across the EU27. In economic terms, the periphery does have the worst outcomes, regardless of the severity of their respective outbreaks. The picture is more mixed in terms of mortality. Nevertheless, the evidence is stacked against any capacity for exiting together the crisis, especially problematic as indicated above in the context of the crisis in the public health arena, which by nature sees no borders even if problematic departures from free-travel are to be maintained as a substantial intra-EU cross-border movement has always remained in place even at highest restriction levels.

From such a perspective Table 4 shows the components emerging from a principal component analysis considering pre-pandemic context, outbreak and policy responses and outcomes in the economic and health arena, accounting for cross-wave differences. Such an exercise provides some backing to the dynamics highlighted in the comparative assessment of the scoreboards. Specifically, two components are indicative of high restrictions (in the first and second wave respectively), low health preparedness (decreasing health expenditures in the austerity era) and low economic responses. From a geographical viewpoint, the core periphery divide is confirmed, as the periphery is better endowed along both components. The divide is especially marked in the context of the component linked to high first wave restrictions and low health budgets, on average in the negative extreme in the core while high in the periphery amounting to a significant difference across geographical fault lines, as shown in Table 
A2. Indeed, periphery countries score systematically at the high extreme - with the sole exception of Spain - on such a component, not only detaining the exclusive of the top rankings, but displaying as first and second Malta and Greece which experienced very mild outbreaks especially in the first wave.

Table 4 - PCA cross-wave data

\begin{tabular}{|l|r|r|r|r|r|}
\hline & Comp1 & Comp2 & Comp3 & Comp4 & Comp5 \\
\hline schools FW & -0.1354 & -0.0901 & 0.3197 & 0.2468 & 0.0046 \\
\hline schools SW & -0.2983 & 0.115 & 0.0456 & 0.3228 & -0.0649 \\
\hline lockdowns FW & 0.2264 & -0.1531 & 0.3299 & 0.2595 & 0.2088 \\
\hline lockdowns SW & 0.2322 & 0.0955 & 0.0695 & 0.4056 & -0.1071 \\
\hline testing FW & 0.2392 & -0.0452 & 0.3344 & -0.2875 & -0.0931 \\
\hline testing SW & 0.2596 & -0.0959 & 0.2757 & -0.1806 & -0.2799 \\
\hline tracing FW & 0.1273 & 0.4488 & 0.1868 & -0.0251 & -0.0922 \\
\hline tracing SW & 0.0795 & 0.3714 & 0.1946 & 0.0476 & -0.1982 \\
\hline cases FW & 0.4 & -0.0327 & -0.0681 & 0.222 & 0.1777 \\
\hline deaths FW & 0.2884 & -0.0099 & -0.0988 & 0.2841 & 0.3977 \\
\hline cases SW & 0.1295 & 0.4431 & -0.0199 & 0.0347 & 0.1048 \\
\hline deaths SW & -0.1525 & 0.4461 & 0.1003 & 0.0904 & 0.2398 \\
\hline stimulus & 0.0496 & 0.0848 & -0.0549 & -0.3659 & 0.084 \\
\hline hospital beds & -0.2934 & 0.3366 & 0.0237 & -0.0343 & -0.0697 \\
\hline$\Delta$ health spending & 0.1812 & 0.1806 & -0.4249 & -0.0519 & -0.0306 \\
\hline pop. density & 0.1855 & 0.0818 & 0.189 & -0.3372 & -0.0034 \\
\hline elderly share & -0.1252 & -0.081 & 0.0477 & -0.2198 & 0.5438 \\
\hline gdp p.c. & 0.4011 & 0.0485 & -0.2136 & 0.0399 & -0.2368 \\
\hline health budget 18 & 0.1484 & 0.1675 & -0.2062 & -0.1976 & 0.328 \\
\hline gdp drop & 0.0526 & 0.0474 & 0.4317 & -0.071 & 0.2748 \\
\hline
\end{tabular}




\section{Covid-19 as a catalyst for health reform}

The Covid-19 impact on European societies and institutions has demonstrated the necessity of major integration in the health sector to face emergencies like Coronavirus. The Member States' hurdles and the limits of the EU juridical framework in this field are critical because of potential future menaces for the Union and the citizens (Anderson et al., 2020).

Within the package of pandemic measures, Europe launched EU4Health, a programme aimed to foster preparedness of EU health systems, promoting cooperation in the health sector among the EU Member States. The programme will promote better health and healthcare in the European Union, focusing on the prevention of diseases. It will focus on preventing cross-border threats, integrating the common reserves of health-related equipment in the European Union to avoid the disruptions of the early pandemic (Regulation, 2021/522). The programme will create a pool of healthcare professionals who can support the country (or the countries) under pressure. Another key aim of the programme will be overseeing medicines costs and promoting sharing of essential data in normal and crisis times (Regulation, 2021/522). The regulation stated that, even if the States hold primary responsibilities in health chapters, they should pursue cooperation and solidarity in this matter, saying clearly that pandemic should improve EU preparedness in the health chapter, including in times of crisis (Regulation, 2021/522). The programme will replace the previous 282/2014 and will be valid for the 2021-2027 timeframe, and the EU will implement it for Health and Digital Executive Agency; the programme should have an initial budget of 500 million EUR. The programme should work as an 'engine' for other initiatives in the health field able to create added value in health-related cooperation within the EU (Regulation, 2021/522).

In addition, the European Commission proposed extending the mandate of both EMA and ECDC and, more importantly, creating another agency, the health emergency preparedness and response authority (HERA) (European Commission, 2020b; European Commission, 2021b). The agency will not replace, but complete, in the view of the EC, the 'EU package' to counteract cross-border menaces within the EU. The new agency could be built on the US Biomedical Advanced Research and Development Authority (BARDA) model, providing stockpiling medical devices, PPEs, Vaccines to ensure a coordinated response in case of need. That will be particularly useful in case of supply chain crises or limits imposed by manufacturers, third countries or even other internal issues (European Commission, 2021b). Another critical asset will be the support to biomedical research advising about possible therapies and vaccines in the infectious diseases' field. In this case, cooperation with ECDC and EMA will be enhanced (European Commission, 2021b). According to the European Commission, the delivery of the new agency could fuel the EU Health Union project ensuring 'a solid framework for EU preparedness, surveillance, risk assessment, early warning and response to all serious cross-border threats to health' (European Commission, 2021b). According to the European Commission, HERA will also improve the Security Union offering a safeguard in case of biological menace to the European Union. The delivery of the project will be in the last part of 2021, according to the timeframe of the European Commission (European Commission, 2021b)

Therefore, summing up, the European Union put in place some attempts to promote and stimulate cooperation among its Members, especially in a critical field where, suddenly, exclusive competence is held by the Member States. However, the proposals of the European Commission, especially the EU4Health are within the boundaries of the current Treaty framework. The proposal to enhance the agency framework by establishing a new one could be an opportunity to establish an effective tool to prepare the EU for potential transnational health. Nonetheless, the question marks come from the recent past: as the history of the ECDC taught to us, the European agencies could recommend, but the Member States (according to art.168 TFEU) are free to apply those measures. The Member States' willingness and commitment to the success of the new agency will determine its future.

It is far from a given that such measures will counteract the ongoing limits in EU Health policy in the current legal framework. Key challenges remain concerning the ability of the EU to react in case of crisis, preparedness of the Member States related also on its pre-existing conditions (e.g., public expenditures on Health chapter; hospital beds; ICUs or distance from the ICUs) remained unsolved. 
The CSRs, in the past, tried to set common standards (Azzopardi-Muscat et al.2015) while pressuring for cost containment revealing in such a large scale health emergency deep inequalities in preparedness, leaving the austerity struck periphery as lagging behind in the trade-off between health infrastructure and restrictions - as well as in its parallel human and economic cost.

Moreover, problems remain open concerning the civil protection mechanism: stockpiling provided, under the coordination of HERA (the newest agency) and establishment of reserve of personnel (within the framework of EU4Health) could offer improvements but considering the scope of the pandemic and the framework established by the Treaty, a hypothetical future emergency could hardly be managed on a voluntary contribution base. All the measures put on the field are still dependent on the voluntary commitment by the Member States to the common efforts in coherence with the new initiatives in the health field. Such a situation showed the limits of coordination in the present legal framework indicating that encompassing and effective solutions may not be foreseen without a revision of competencies according to subsidiarity - allowing when necessary for substantial prerogatives for the supranational level. Hence, the tragedy of the pandemic, notwithstanding the far from trivial improvements in awareness for the need of greater health coordination and the (partial) policy measures to follow, provides a solid case for treaty reform. From such a perspective, Covid-19 has touched a raw nerve and political third rail of multilevel governance in the EU, which grounds a call for the establishment of a genuine Health Union, able to ensure direct action at the European level and overcome critical shortcomings in health governance within the old continent (Bartlett 2020; Bazzan 2020). The support of a coherent supranational health policy would also benefit from the developing EU fiscal powers as the novel pandemic recovery instrument of Next Generation EU could help to create effective capabilities to reinforce health preparedness in weaker Member States and managing cross-border threats - another arena, however, in which the Covid-19 crisis and its temporary emergency response mechanism is a powerful indication of the need for further integration and revision of the Treaties.

\section{The country road towards a Health Union}

The work has considered how the EU multilevel governance framework - or lack thereof - in the health domain, along with spillovers from the austerity-driven Economic Monetary Union has contributed to shaping the deeply unequal circumstances in which the Member States entered the pandemic, a dynamic substantiated both by the overview of the literature on the legacy of the sovereign debt crisis in section two and the empirical analysis in section five. The scrutiny of the EU health governance and (limited) coordination in this arena in the context of the Covid-19 crisis in sections three and four highlights that the implication of such heterogeneities, paired with limited scope for coordination are twofold. On one side, there was large-scale cramming both in the economic and health domains in pushing the boundaries of existing competencies in deploying emergency response mechanisms and coordinated action to cope with the crisis pandemic. On the other, the governance architecture (and political conflict) left limited options - especially in the early phase - but to leave the Member States alone in shouldering the health and economic tragedy of the pandemic. A circumstance which turned into fragmented success in tackling contagion and preventing tragic consequences for health and the economy across the Union, with marked geographic inequalities, as shown by the empirical comparative assessment of the context, outbreak, policy responses and outcomes across the EU27. Such a picture is problematic per se given the implied sharp inequalities across the Union in the heat of the Covid-19 crisis and the medium-to-long term as the recovery unfolds, with diverging implications hard to reconcile with the sustainability of the EMU and especially the Eurozone. Additionally, it is especially detrimental in the context of a crisis with transboundary implications and spill-overs in a highly integrated and interdependent regional context such as the EU27.

Specifically, concerning the research questions outlined in the paper, the quantitative and qualitative analysis findings can be summarised as follows.

[1] The pre-pandemic context is characterized by high levels of cross-country inequalities. EU economic governance and austerity policies have contributed to widening such a divide. Without any substantial and effective mitigation policy in the health domain protecting such vital policy area, the result has been markedly different levels of pandemic preparedness across the EU27.

[2] Covid-19 responses across the EU27 were indeed fragmented, denoting a sharp divide along the core-periphery fault line. Countries in the South of Europe emerge as generally paying a 
higher price in their health sector from the austerity spree following the Great Recession and Sovereign debt crisis. Regardless of the severity of the outbreak they experienced, their responses proportionally highly relied on restrictions while in most instances displayed weaker fiscal support. In parallel, they displayed more costly outcomes both in human and economic terms. Such patterns indicate deep cross-country variations in the effectiveness of crisis management and limited EU coordination, with linkages across inputs, pandemic outputs and outcomes backed by the Principal Component analysis.

[3] Because of the transboundary implications highlighted above such patterns providing a strong case for further integration indicated by the Covid-19 crisis. Partial progress has been made in the heat of the crisis - for example through the implementation of joint vaccine procurement and the Green Pass - but not without the limits and difficulties of a governance infrastructure illequipped with the powers and the tools to act at the supranational level. Additionally, while further proposals for a Health Union have been put forwards, short of Treaty reform many of the constraints evidenced by the pandemic remain.

Such findings provide strong support for the key argument of Covid-19 acting as a powerful case for the limits and unfitness of the current EU health governance framework, especially in contexts such as public health in which transnational interdependence and spill-overs abound. Short of ambitious progress in integration exceeding the boundaries of the Treaties, fragmentation and inequalities amount to excruciating complications in a timely exit from the crisis. The need for deeper coordination in the health sectors and the dangers of overarching inequalities within the Union - in a context in which health and social policies have often been pushed as adjustment spaces under the primacy of fiscal discipline - is hence the primary conclusion of this work. In addition, dynamics showed the continued relevance of crises as a powerful pressure for further developments at times overcoming entrenched political divisions and red lines such as in the launch of Next Generation EU, which at least temporarily saw a suspension of vetoes in transnational solidarity and common borrowing. A parallel can be drawn in the health arena, where the support of the European Institutions was sought to provide coordination and rescue the Member States for the crippling consequences of the pandemic, providing fair and universal access to vaccines and easing travel through the Green Passport. Further innovations such as EU4H and HERA have been proposed. Nevertheless, all innovations are along the margin of the limited EU competencies and hence largely voluntary cooperation which remains unchanged. Similarly, it can hardly be argued that the result would be conversely overwhelming and on par with the enormous challenges and geographical divides highlighted by the pandemic. Indeed, while progress of health integration and coordination is undeniable, the evaluation against the benchmark of mitigating sharp health inequality is likewise indubitably unsatisfactory. The analysis additionally serves to pinpoint the cross-policy interdependencies and potential collateral damage of policies enacting stringent fiscal discipline over any other societal concern. Such results are especially timely as the crisis may continue to offer a window of opportunity for enhanced solidarity and willingness to support common solutions and in particular, as the prospects of integration are under discussion in the context of the Conference on the Future of Europe.

A few words of caution are warranted in seeing the Covid-19 outbreak as a critical juncture shifting towards an ever closer Health Union. Firstly, if crises have been key in the progress of European integration, their engine in a context of intergovernmental decision making and primacy of the Member States and national interest has been shown in the past as potentially flawed in another sensitive area such as fiscal policies. Indeed, the failing forwards argument hinges on the interaction between functionalist pressure to deepen integration and divisive intergovernmental process, delivering underwhelming solutions which set the premises for further governance failures and crises (Jones et al., 2016). Hence whether Covid-19 will be sufficient to lead to a permanent gear shift in the health arena is far from straightforward. The remaining high level of contestation - and blame game towards the EU for example concerning the initial delays of the vaccination campaign supports some weariness in considering recent developments as a sharp turn toward a path of solidarity. The nature of solidarity itself warrants some scrutiny: in a context of emergency politics arguably transnational support for common solutions can be easily considered a "solidarity of necessity" rather than of "community" (Raspotnik et al., 2012). A substantial challenge to overcome even in a context of a blame-free crisis of disaster-line nature such as Covid-19, given its severely asymmetric impact across the geographical and political divide of the core and periphery. 


\section{References}

Anderson, M., Mckee, M., \& Mossialos, E. (2020). Covid-19 exposes weaknesses in European response to outbreaks. BMJ, m1075. https://doi.org/10.1136/bmj.m1075

Andor, L. (2017) 'The Impact of Eurozone Governance on Welfare Stability'. In Vandenbroucke, F., Barnard, C. and De Bare, G. (eds) A European Social Union after the Crisis (Cambridge: Cambridge University Press), pp. 143-59

Annane, D., Federici, L., Chagnon, J.-L., Diehl, J. L., Dreyfuss, D., Guiot, P., Javouhey, E., Joram, N., Lesieur, O., Rigaud, J. P., Outin, H., Sement, A., Sevens, C., Thévenin, D., Touati, S., \& Terzi, N. (2021). Intensive care units, the Achilles heel of France in the COVID-19 battle. The Lancet Regional Health - Europe, 2, 100046. https://doi.org/10.1016/J.LANEPE.2021.100046

Antonova, L., Bucher-Koenen, T., \& Mazzonna, F. (2017). Long-term health consequences of recessions during working years. Social Science \& Medicine, 187, 134-143. https://doi.org/10.1016/i.socscimed.2017.06.025

Armingeon, K., Guthmann, K., \& Weisstanner, D. (2016). How the Euro divides the union: The effect of economic adjustment on support for democracy in Europe. Socio-Economic Review, 14(1), 1-26. https://doi.org/10.1093/ser/mwv028

Azzopardi-Muscat, N., Clemens, T., Stoner, D., \& Brand, H. (2015). EU Country Specific Recommendations for health systems in the European Semester process: Trends, discourse and predictors. Health Policy, 119(3), 375-383. https://doi.org/10.1016/i.healthpol.2015.01.007

Barbieri, T., Basso, G., \& Scicchitano, S. (2020). Italian Workers at Risk during the COVID-19 Epidemic. SSRN Electronic Journal. https://doi.org/10.2139/ssrn.3572065

Bartlett, O. (2020). COVID-19, the European Health Union and the CJEU: Lessons from the Case Law on the Banking Union. European Journal of Risk Regulation, 11(4), 781-789.

https://doi.org/10.1017/err.2020.78

Bauer, J., Brüggmann, D., Klingelhöfer, D., Maier, W., Schwettmann, L., Weiss, D. J., \& Groneberg, D. A. (2020). Access to intensive care in 14 European countries: a spatial analysis of intensive care need and capacity in the light of COVID-19. Intensive Care Medicine, 46(11), 2026-2034. https://doi.org/10.1007/s00134-020-06229-6

Bazzan, G. (2020). Exploring Integration Trajectories for a European Health Union. European Journal of Risk Regulation, 11(4), 736-746. https://doi.org/10.1017/err.2020.98

Bieber, F. (2020). Global Nationalism in Times of the COVID-19 Pandemic. Nationalities Papers, 1-13. https://doi.org/10.1017/nps.2020.35

Bollyky, T. J., \& Bown, C. P. (2020). The Tragedy of Vaccine Nationalism. Foreign Affairs, 99(5), 96-108.

Brooks, E. (2012). Crossing borders: A critical review of the role of the European Court of Justice in EU health policy. Health Policy, 105(1), 33-37. https://doi.org/10.1016/J.HEALTHPOL.2011.12.004

Brooks, E., Greer, S. L., \& de Ruijter, A. (2021). Covid-19 and European Union health policy: from crisis to collective action. In B. Vanhercke, S. Spasova, \& B. Fronteddu (Eds.), Social Policy in the European Union: state of play 2020 (pp. 33-53). OSE-ETUI. https://doi.org/D/2021/10.574/01

Bulfone, F., \& Tassinari, A. (2020). Under pressure. Economic constraints, electoral politics and labour market reforms in Southern Europe in the decade of the Great Recession. European Journal of Political Research. https://doi.org/10.1111/1475-6765.12414

Camous, A., \& Claeys, G. (2020). The evolution of European economic institutions during the COVID-19 crisis. European Policy Analysis, 6(2), 328-341. https://doi.org/10.1002/epa2.1100 
Celi, G., Guarascio, D., \& Simonazzi, A. (2020). A fragile and divided European Union meets Covid-19: further disintegration or 'Hamiltonian moment'? Journal of Industrial and Business Economics, 47(3), 411-424. https://doi.org/10.1007/s40812-020-00165-8

Censolo, R., \& Colombo, C. (2016). The impact of the crisis on fiscal convergence in the EU: the early signs. Journal of European Integration, 38(6), 703-717. https://doi.org/10.1080/07036337.2016.1177044

Ceron, M., \& Palermo, C. M. (2020). La risposta alla pandemia in Francia, Germania, Italia e Spagna durante la prima ondata (Pandemic Response in France, Germany, Italy and Spain during COVID-19 First Wave). SSRN Electronic Journal. https://doi.org/10.2139/ssrn.3746658

Ceron, M., Palermo, C. M., \& Salpietro, V. (2020). Limiti e prospettive della gestione europea durante la pandemia da Covid-19. Biblioteca Della Libertà, 55(228). https://doi.org/10.23827/BDL 202023

Ceron, M., Palermo, C. M., \& Grechi, D. (2021). Covid-19 Response Models and Divergences Within the EU: A Health Dis-Union. Statistics, Politics and Policy. https://doi.org/10.1515/spp-2021-0003

Chinazzi, M., Davis, J. T., Ajelli, M., Gioannini, C., Litvinova, M., Merler, S., Pastore y Piontti, A., Mu, K., Rossi, L., Sun, K., Viboud, C., Xiong, X., Yu, H., Halloran, M. E., Longini, I. M., \& Vespignani, A. (2020). The effect of travel restrictions on the spread of the 2019 novel coronavirus (COVID-19) outbreak. Science, 368(6489), 395-400. https://doi.org/10.1126/science.aba9757

Clancy, M. (2020). The Case for Remote Work. Economics Working Papers, 4(20007), 1-40. https://lib.dr.iastate.edu/econ workingpapers\%0Ahttps://lib.dr.iastate.edu/econ workingpapers/102

Clemens, T., Michelsen, K., \& Brand, H. (2014). Supporting health systems in Europe: added value of EU actions? Health Economics, Policy and Law, 9(1), 49-69.

Correia, S., Luck, S., \& Verner, E. (2020). Pandemics Depress the Economy, Public Health Interventions Do Not: Evidence from the 1918 Flu. SSRN Electronic Journal. https://doi.org/10.2139/ssrn.3561560

Crespy, A. (2020). The EU's Socioeconomic Governance 10 Years after the Crisis: Muddling through and the Revolt against Austerity. JCMS: Journal of Common Market Studies, 58(S1), 133-146. https://doi.org/10.1111/jcms.13083

Crespy, A. and Menz, G. (2015). Introduction: The Pursuit of Social Europe in the Face of Crisis. In Crespy, A. and Menz, G. (eds) Social Policy and the Eurocrisis. Quo Vadis Social Europe (Basingstoke: Palgrave), pp. 1-23.

De Grauwe, P., \& Ji, Y. (2018). Core-periphery relations in the eurozone. Economists' Voice, 15(1), 1-16. https://doi.org/10.1515/ev-2018-0027

De la Porte, C., \& Jensen, M. D. (2021). The next generation: An analysis of the dimensions of conflict behind the deal. Social Policy \& Administration, 55(2), 388-402. https://doi.org/10.1111/spol.12709

De Ruijter, A. (2019). EU Health Law \& Policy: The Expansion of EU Power in Public Health and Health Care. Oxford University Press.

Decision No 1082/2013/EU of the European Parliament and of the Council of 22 October 2013 on serious cross-border threats to health and repealing Decision No 2119/98/ECText with EEA relevance (europa.eu)

Delhomme, V. (2020). Emancipating Health from the Internal Market: For a Stronger EU (Legislative) Competence in Public Health. European Journal of Risk Regulation, 11(4), 747-756. https://doi.org/10.1017/err.2020.85

Della Porta, D. (2015). Social Movements in Times of Austerity (Cambridge: Polity Press).

Deruelle, T. (2016). Bricolage or Entrepreneurship? Lessons from the Creation of the European Centre for Disease Prevention and Control. European Policy Analysis. https://doi.org/10.18278/epa.2.2.4 
Deruelle, T., \& Engeli, I. (2021). The COVID-19 crisis and the rise of the European Centre for Disease Prevention and Control (ECDC). West European Politics, 44(5-6), 1376-1400. https://doi.org/10.1080/01402382.2021.1930426

De Maio, G. (2021). EU learns from mistakes on vaccines. Brookings Blog. https://www.brookings.edu/blog/order-from-chaos/2021/05/20/eu-learns-from-mistakes-onvaccines/

Directive 2014/24/EU of the European Parliament and of the Council of 26 February 2014 on public procurement and repealing Directive 2004/18/EC https://eur-lex.europa.eu/legal-content/en/TXT/?uri=CELEX:32014L0024

Egeberg, M., \& Trondal, J. (2011). EU-level agencies: new executive centre formation or vehicles for national control? Journal of European Public Policy, 18(6), 868-887. https://doi.org/10.1080/13501763.2011.593314

Eikemo, T. A., Bambra, C., Huijts, T., \& Fitzgerald, R. (2017). The first pan-european sociological health inequalities survey of the general population: The european social survey rotating module on the social determinants of health. European Sociological Review, 33(1), 137-153. https://doi.org/10.1093/esr/jcw019

European Commission. (2020a). Coronavirus : la Commissione raccomanda la revoca parziale e graduale delle restrizioni dei viaggi verso l'UE dopo il 30 giugno sulla base di un approccio comune coordinato (pp. 30-32). https://ec.europa.eu/commission/presscorner/detail/it/IP 201035

European Commission. (2020b). Regulation Of the European Parliament and of the Council amending Regulation (EC) 851/2004 establishing a European Center for Disease prevention and Control. https://ec.europa.eu/info/sites/default/files/proposal-mandate-european-centre-disease-preventioncontrol en.pdf

European Commission. (2021a). EU Digital COVID Certificate. European Commission. https://ec.europa.eu/info/live-work-travel-eu/coronavirus-response/safe-covid-19-vaccineseuropeans/eu-digital-covid-certificate en

European Commission. (2021b). European Health Emergency Preparedness and Response Authority (eds. DG Health and Food Safety (Unit C3: Health security and vaccination) (Vol. 59, Issue 2019, pp. 1-5).

Forster, T., \& Kentikelenis, A. E. (2019). Austerity and health in Europe: disentangling the causal links. European Journal of Public Health, 29(5), 808-809. https://doi.org/10.1093/eurpub/cky249

Forster, T., Kentikelenis, A., \& Bambra, C. (2018). Health Inequalities in Europe: Setting the Stage for Progressive Policy Action. 13-71.

https://www.tasc.ie/assets/files/pdf/18456 health inequalities finalweb.pdf

Gräbner, C., Heimberger, P., \& Kapeller, J. (2020). Pandemic pushes polarisation: the Corona crisis and macroeconomic divergence in the Eurozone. Journal of Industrial and Business Economics, 47(3), 425-438. https://doi.org/10.1007/s40812-020-00163-w

Greer, S.L. (2012a). Polity-making without Policy-making: European Union Healthcare Services Policy. In Constructing a Policy-Making State? (pp. 270-291). Oxford University Press. https://doi.org/10.1093/acprof:oso/9780199604104.003.0014

Greer, S. L. (2006). Uninvited Europeanization: neofunctionalism and the EU in health policy. Journal of European Public Policy, 13(1), 134-152.

Greer, S. L. (2012b). The European Centre for Disease Prevention and Control: Hub or Hollow Core? Journal of Health Politics, Policy and Law, 37(6), 1001-1030. https://doi.org/10.1215/03616878$\underline{1813817}$

Greer, S. L. (2020a). National, European, and global solidarity: COVID-19. Eurohealth, 26(2), 104-112. 
Greer, S. L. (2020b). Health, Federalism, and the European Union: Lessons from Comparative Federalism about the European Union. Health Economics, Policy, and Law, April 30. doi.org/10.1017/S1744133120000055.

Greer, S. L., \& de Ruijter, A. (2020). EU health law and policy in and after the COVID-19 crisis. European Journal of Public Health, 30(4), 623-624. https://doi.org/10.1093/eurpub/ckaa088

Greer, S. L., \& Jarman, H. (2018). European Citizenship Rights and European Fiscal Politics After the Crisis. Government and Opposition, 53(1), 76-103. https://doi.org/10.1017/gov.2016.2

Greer, S. L., \& Löblová, O. (2016). European integration in the era of permissive dissensus: Neofunctionalism and agenda-setting in European health technology assessment and communicable disease control. Journal of Public Health Policy, 15, 394-413. https://doi.org/10.1057/cep.2016.6

Greer, S. L., and Jarman, Holly. (2021). What Is EU Public Health and Why? Explaining the Scope of Public Health in the European Union. Journal of Health Politics, Policy and Law 46, no. 1: 23-48.

Greer, S. L., de Ruijter, A., \& Brooks, E. (2021). The COVID-19 pandemic: Failing forward in public health. In The Palgrave Handbook of EU Crises (pp. 747-764). Springer.

Greer, S. L., Jarman, H., Rozenblum, S., \& Wismar, M. (2020). Centralisation Within and Between Governments. Eurohealth, 26(2), 99-103.

Greer, S. L., King, E., Massard da Fonseca, E., \& Peralta-Santos, A. (2021). Coronavirus Politics (S. L. Greer, E. King, E. Massard da Fonseca, \& A. Peralta-Santos (eds.)). University of Michigan Press. https://doi.org/10.3998/mpub.11927713

Guardiancich, I., \& Guidi, M. (2020). The political economy of pension reforms in Europe under financial stress. Socio-Economic Review, O(0), 1-24. https://doi.org/10.1093/ser/mwaa012

Guillén, A. M., González-Begega, S., \& Balbona, D. L. (2016). Austerity and social retrenchment in Southern Europe. the fragmentation of the Mediterranean welfare model . Revista Espanola de Sociologia, 25(2), 261-272.

Guy, M. (2017). The history and scope of EU health law and policy. Research Handbook on EU Health Law and Policy, (Routledge), 17-35. https://doi.org/10.4337/9781785364723.00012

Guy, M. (2020). Towards a European Health Union: What Role for Member States? In European Journal of Risk Regulation (Vol. 11, Issue 4, pp. 757-765). Cambridge University Press. https://doi.org/10.1017/err.2020.77

Herreros, B., Gella, P., \& Real De Asua, D. (2020). Triage during the COVID-19 epidemic in Spain: Better and worse ethical arguments. Journal of Medical Ethics, 455-458. https://doi.org/10.1136/medethics2020-106352

Herszenhorn, D. M., \& Vela, J. H. (2020). European Commission to propose tougher vaccine export rules. Politico Europe. https://www.politico.eu/article/commission-to-table-tougher-vaccine-export-rules/

Herszenhorn, D. M., \& Vela, J. H. (2021). EU brandishes export ban to claim dibs on vaccines. Politico Europe. https://www.politico.eu/article/eu-brandishes-export-ban-to-claim-dibs-on-vaccineastrazeneca-pfizer/

Holland, W. W. (2012). Austerity: A failed experiment on the people of Europe. Clinical Medicine, Journal of the Royal College of Physicians of London, 12(6), 603-604. https://doi.org/10.7861/clinmedicine.12$\underline{6-603 a}$

Howarth, D., \& Verdun, A. (2020). Economic and Monetary Union at twenty: a stocktaking of a tumultuous second decade: introduction. Journal of European Integration, 42(3), 287-293.

Jordana, J., \& Triviño-Salazar, J. C. (2020). Where are the ECDC and the EU-wide responses in the COVID-19 pandemic? The Lancet, 395(10237), 1611-1612. https://doi.org/10.1016/S0140$\underline{6736(20) 31132-6}$ 


\section{APSA 2021 - COVID-19 and Disparities}

Jones, E., Kelemen, R. D., \& Meunier, S. (2016). Failing Forward? The Euro Crisis and the Incomplete Nature of European Integration. Comparative Political Studies, 49(7), 1010-1034. https://doi.org/10.1177/0010414015617966

Karanikolos, M., Mladovsky, P., Cylus, J., \& al., et. (2013). Financial crisis, austerity, and health in Europe. Lancet, 381, 1323-1331.

Kerem, K., Puss, T., Viies, M., \& Maldre, R. (2008). Health and convergence of health care expenditure in EU. International Business \& Economics Research Journal (IBER), 7(3).

Lamping, W. (2013) EU health care policy. In Greer, S. L. \& Kurzer, P. (eds) European Union Public Health Policy - Regional and Global Trends (Routledge).

Lau, C. K. M., Fung, K. W. T., \& Pugalis, L. (2014). Is health care expenditure across Europe converging? Findings from the application of a nonlinear panel unit root test. Eurasian Business Review, 4(2), 137-156. https://doi.org/10.1007/s40821-014-0014-9

Linka, K., Peirlinck, M., Sahli Costabal, F., \& Kuhl, E. (2020). Outbreak dynamics of COVID-19 in Europe and the effect of travel restrictions. Computer Methods in Biomechanics and Biomedical Engineering, 23(11), 710-717. https://doi.org/10.1080/10255842.2020.1759560

Makszin, K., Medve-Bálint, G. \& Bohle, D. (2020). North and South, East and West: Is it Possible to Bridge the Gap? In Coman, R., Crespy, A. \& Schmidt, V.A. (eds) Governance and Politics in the Post-crisis European Union (Cambridge: Cambridge University Press), pp. 335-57.

Marmot, M. (2013). Health inequalities in the EU. Final report of a consortium. European Commission Directorate-General for Health and Consumers.

Marmot, M., Bloomer, E., \& Goldblatt, P. (2013). The role of social determinants in tackling health objectives in a context of economic crisis. Public Health Reviews, 35(1), 1-24. https://doi.org/10.1007/BF03391694

Marques, P., \& Hörisch, F. (2020). Understanding massive youth unemployment during the EU sovereign debt crisis: a configurational study. Comparative European Politics, 18(2), 233-255. https://doi.org/10.1057/s41295-019-00184-3

Mascio, F. Di, Natalini, A., Ongaro, E., \& Stolfi, F. (2020). Influence of the European Semester on national public sector reforms under conditions of fiscal consolidation: The policy of conditionality in Italy 2011-2015. Public Policy and Administration, 35(2), 201-223. https://doi.org/10.1177/0952076718814892

Matthijs, M. (2017). Integration at What Price? The Erosion of National Democracy in the Euro Periphery. Government and Opposition, 52(2), 266-294. https://doi.org/10.1017/gov.2016.50

Matthijs, M., \& Merler, S. (2020). Mind the Gap: Southern Exit, Northern Voice and Changing Loyalties since the Euro Crisis. JCMS: Journal of Common Market Studies, 58(1), 96-115. https://doi.org/10.1111/jcms.12984

Notermans, T., \& Piattoni, S. (2020). EMU and the Italian debt problem: destabilising periphery or destabilising the periphery? Journal of European Integration, 42(3), 345-362. https://doi.org/10.1080/07036337.2020.1730353

Opiłowska, E. (2021). The Covid-19 crisis: the end of a borderless Europe? European Societies, 23(sup1), S589-S600. https://doi.org/10.1080/14616696.2020.1833065

Pagoulatos, G. (2020). EMU and the Greek crisis: testing the extreme limits of an asymmetric union. Journal of European Integration, 42(3), 363-379. https://doi.org/10.1080/07036337.2020.1730352

Palermo, C. M. (2020). Covid-19: US and EU, Why the Outbreak Could Induce an Institutional Evolution. SSRN Electronic Journal, March. https://doi.org/10.2139/ssrn.3568215 


\section{APSA 2021 - COVID-19 and Disparities}

Papadopoulos, T., \& Roumpakis, A. (2018). Rattling Europe's ordoliberal 'iron cage': the contestation of austerity in Southern Europe. Critical Social Policy, 38(3), 505-526. https://doi.org/10.1177/0261018318766987

Papadopoulos, Y. (2020). Eurozone crisis management and the changing nature of the democratic deficit in the European Union. In The European Social Model under Pressure (pp. 567-581). Wiesbaden: Springer Fachmedien Wiesbaden. https://doi.org/10.1007/978-3-658-27043-8 32

Perugini, C., Rakić, J. Ž., \& Vladisavljević, M. (2019). Austerity and gender inequalities in Europe in times of crisis. Cambridge Journal of Economics, 43(3), 733-768. https://doi.org/10.1093/cje/bey044

Quaglio, G. L., Karapiperis, T., Van Woensel, L., Arnold, E., \& McDaid, D. (2013). Austerity and health in Europe. Health Policy, 113(1-2), 13-19. https://doi.org/10.1016/i.healthpol.2013.09.005

Raspotnik, A., Jacob, M., \& Ventura, L. (2012). DISCUSSION PAPER THE ISSUE OF SOLIDARITY IN THE EUROPEAN UNION. TEPSA Pre-Presidency Conference 14-15 June 2012 Cypriot EU Presidency 2012: Institutional Consolidation and Responding to New Challenges Plenary Session 14 June 17.00-19.00 Which Kind of Solidarity? An Analysis of the Sharpened Debate on the EU in the Mem, 1-13. http://www.tepsa.eu/download/TEPSA Discussion Paper The issue of solidarity in the European Union.pdf

Regulation (EU) 2021/522 establishing a Programme for the Union's action in the field of health ('EU4Health Programme') for the period 2021-2027, and repealing Regulation (EU) No 282/2014

Renda, A., \& Castro, R. (2020). Towards stronger EU governance of health threats after the Covid-19 pandemic. European Journal of Risk Regulation, 11(2), 273-282. https://doi.org/10.1017/err.2020.34

Rhodes, A., Ferdinande, P., Flaatten, H., Guidet, B., Metnitz, P. G., \& Moreno, R. P. (2012). The variability of critical care bed numbers in Europe. Intensive Care Medicine, 38(10), 1647-1653. https://doi.org/10.1007/s00134-012-2627-8

Rittberger, B., \& Wonka, A. (2011). Introduction: agency governance in the European Union. Journal of European Public Policy, 18(6), 780-789. https://doi.org/10.1080/13501763.2011.593356

Rokicki, T., Perkowska, A., \& Ratajczak, M. (2021). Differentiation in healthcare financing in eu countries. Sustainability, 13(1), 1-18. https://doi.org/10.3390/su13010251

Ruiz-Rufino, R., \& Alonso, S. (2017). Democracy without choice: Citizens' perceptions of government autonomy during the Eurozone crisis. European Journal of Political Research, 56(2), 320-345. https://doi.org/10.1111/1475-6765.12187

Santos Rutschman, A. (2020). The Reemergence of Vaccine Nationalism. SSRN Electronic Journal. https://doi.org/10.2139/ssrn.3642858

Santos, J. V., Souza, J., Valente, J., Alonso, V., Ramalho, A., Viana, J., Ricciardi, V. and Freitas, A. (2020). The state of health in the European Union (EU-28) in 2017: An analysis of the burden of diseases and injuries. European Journal of Public Health, 30(3), 573-578. https://doi.org/10.1093/eurpub/ckz203

Schnabe, I. (2020). Unequal scars - distributional consequences of the pandemic. https://www.ecb.europa.eu/press/key/date/2020/html/ecb.sp200918 8aaf49cd79.en.html

Seychell, M., \& Hackbart, B. (2013). The EU Health Strategy_Investing in Health. Public Health Reviews, $35(1), 4$

Seyfi, S., Hall, C. M., \& Shabani, B. (2020). COVID-19 and international travel restrictions: the geopolitics of health and tourism. Tourism Geographies, 1-17. https://doi.org/10.1080/14616688.2020.1833972

Shafer, K., Milkie, M., \& Scheibling, C. (2020). The Division of Labour Before and During the COVID-19 Pandemic in Canada. SocArXiv https://doi.org/10.31235/osf.io/24j87 


\section{APSA 2021 - COVID-19 and Disparities}

Sorensen, K., Clemens, T., \& Rosenkotter, N. (2013). The EU's health mandate after 20 years: the glass is half full. The European Journal of Public Health, 23(6). https://doi.org/10.1093/eurpub/ckt164

Souza, K. R. de, Santos, G. B. dos, Rodrigues, A. M. dos S., Felix, E. G., Gomes, L., Rocha, G. L. da, Conceição, R. do C. M., Rocha, F. S. da, \& Peixoto, R. B. (2021). Trabalho remoto, saúde docente e greve virtual em cenário de pandemia. Trabalho, Educação e Saúde, 19. https://doi.org/10.1590/1981-7746-sol00309

Stuckler, D., Reeves, A., Loopstra, R., Karanikolos, M., \& McKee, M. (2017). Austerity and health: the impact in the UK and Europe. European Journal of Public Health, 27(suppl_4), 18-21. https://doi.org/10.1093/eurpub/ckx167

Terzi, A. (2020). Macroeconomic adjustment in the euro area. European Economic Review, 128. https://doi.org/10.1016/i.euroecorev.2020.103516

Toffolutti, V., \& Suhrcke, M. (2019). Does austerity really kill? Economics and Human Biology, 33, $211-$ 223. https://doi.org/10.1016/i.ehb.2019.03.002

Torjesen, I. (2021). Covid-19 vaccine shortages: what is the cause and what are the implications? BMJ, n781. https://doi.org/10.1136/bmj.n781

van der Wel, K. A., Saltkjel, T., Chen, W. H., Dahl, E., \& Halvorsen, K. (2018). European health inequality through the 'Great Recession': social policy matters. Sociology of Health and IIIness, 40(4), 750-768. https://doi.org/10.1111/1467-9566.12723

Verschuuren, M., Gissler, M., Kilpeläinen, K., Tuomi-Nikula, A., Sihvonen, A.-P., Thelen, J., Prochorskas, R. (2013). Public health indicators for the EU: the joint action for ECHIM (European Community Health Indicators \& Monitoring). Archives of Public Health, 71(1), 1-7.

Villaverde, J., Maza, A., \& Hierro, M. (2014). Health care expenditure disparities in the European Union and underlying factors: A distribution dynamics approach. International Journal of Health Care Finance and Economics, 14(3), 251-268. https://doi.org/10.1007/s10754-014-9147-8

Wonka, A., \& Rittberger, B. (2010). Credibility, Complexity and Uncertainty: Explaining the Institutional Independence of 29 EU Agencies. West European Politics, 33(4), 730-752. https://doi.org/10.1080/01402381003794597

Wyplosz, C. (2017). The Eurozone Crisis: A Near-Perfect Case of Mismanagement. In Political Economy Perspectives on the Greek Crisis (Vol. 2009, pp. 41-59). Cham: Springer International Publishing. https://doi.org/10.1007/978-3-319-63706-8 2 


\section{Appendix}

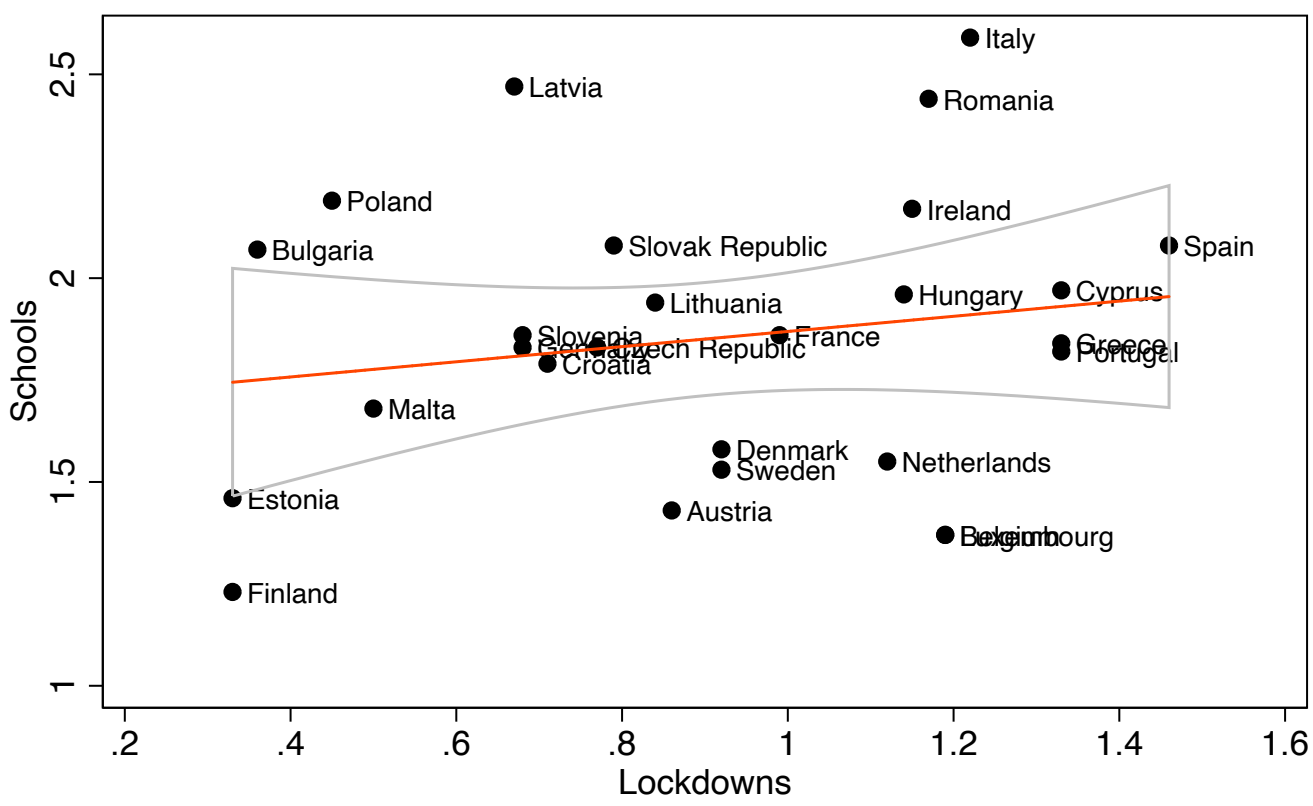

- Schools $\square 95 \% \mathrm{Cl}$

Fitted values

Figure A1 - Lockdowns vs school closures across the EU27

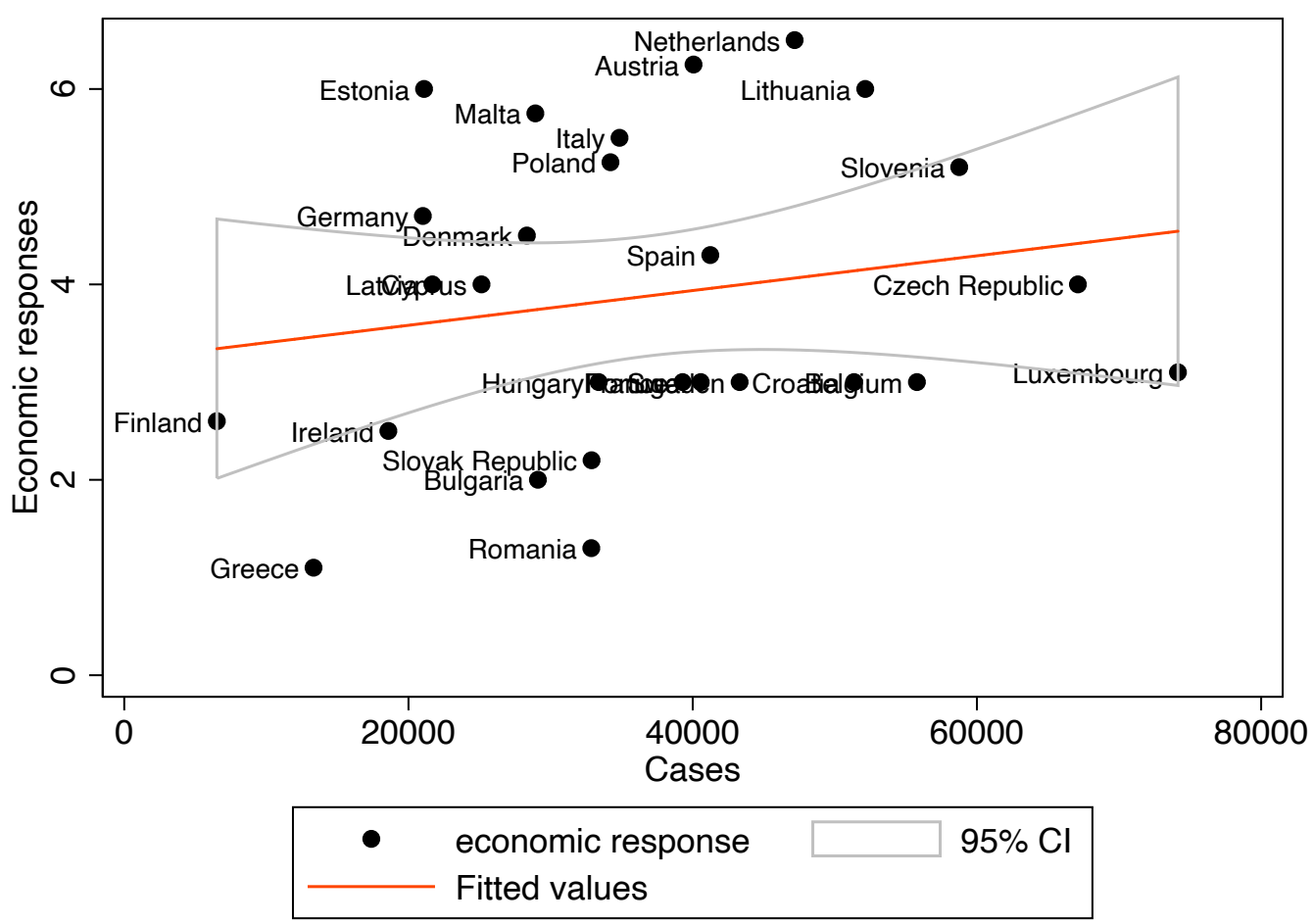

Figure A2 - Cases vs economic responses the EU27 


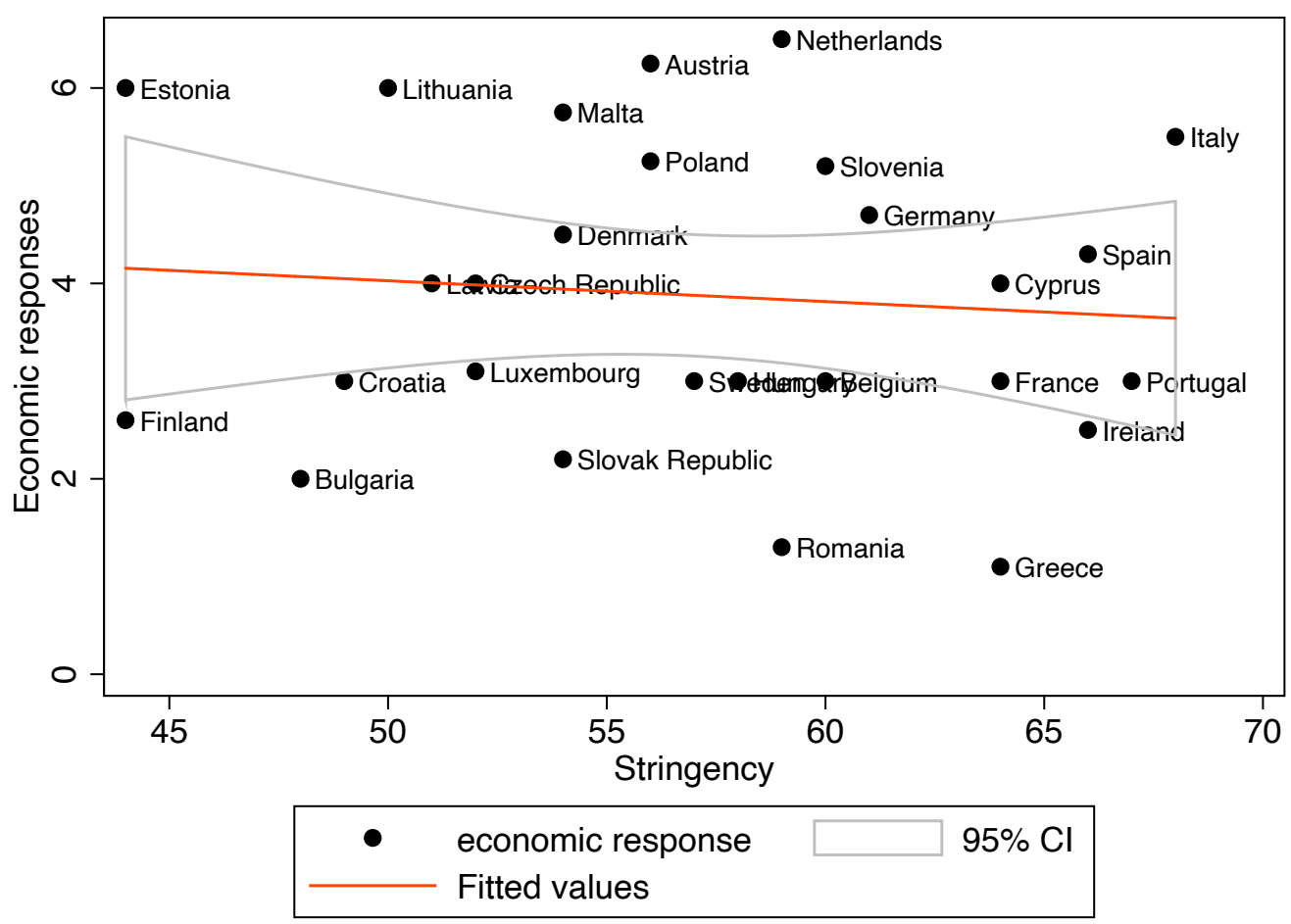

Figure A3 - Stringency vs economic responses across the EU27

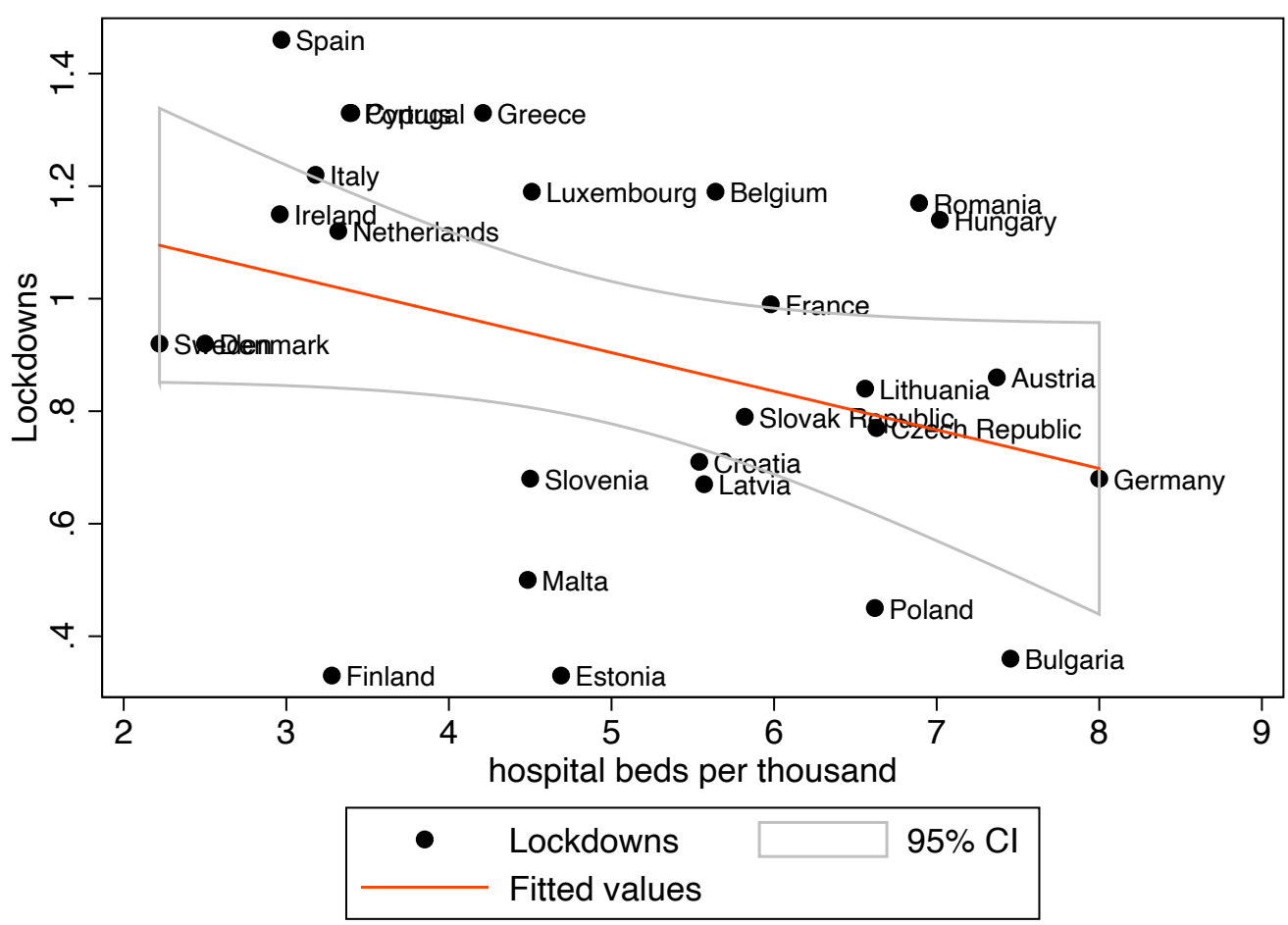

Figure A4 - Hospital beds vs lockdowns across the EU27 


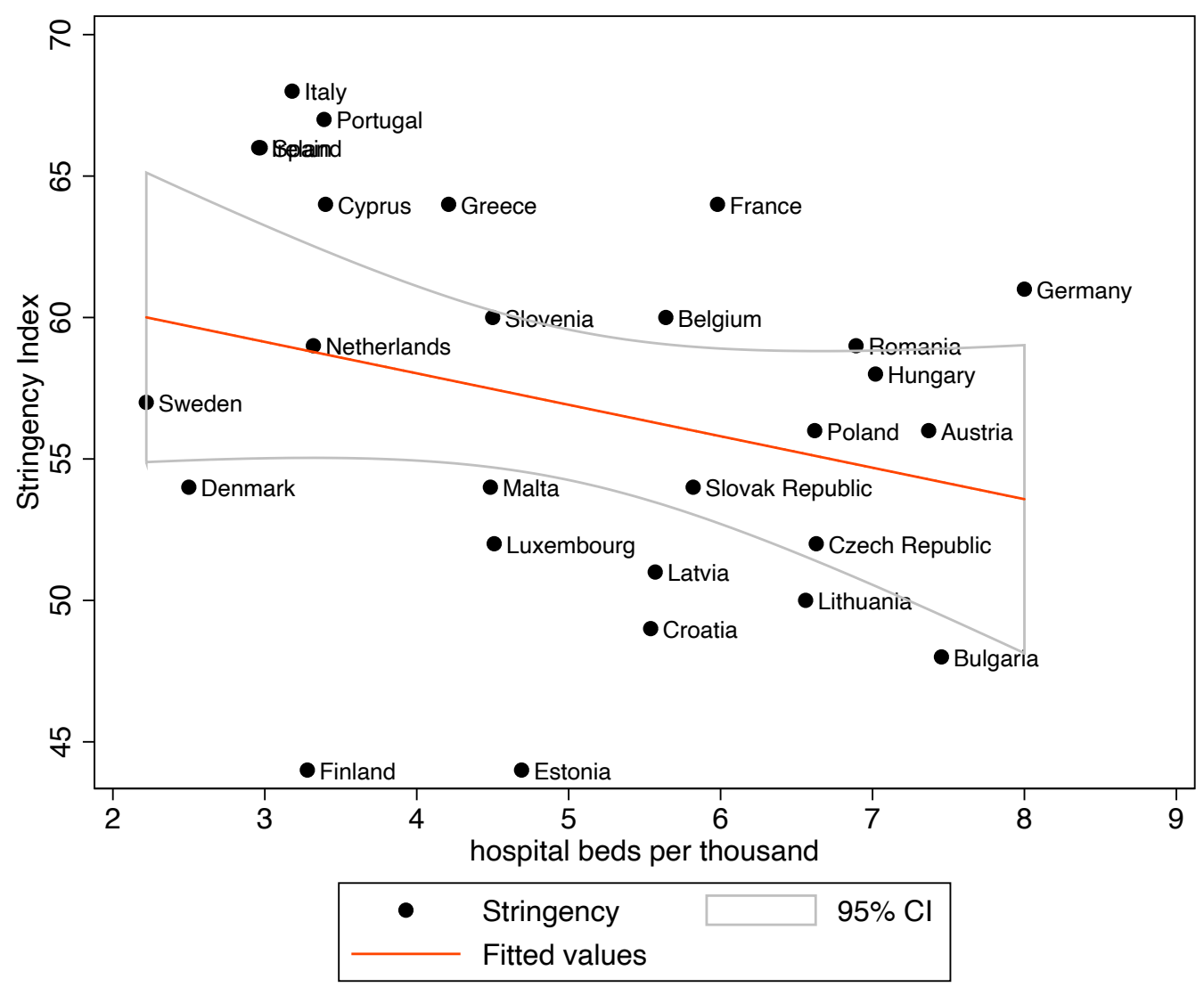

Figure A5 - Hospital beds vs stringency index across the EU27

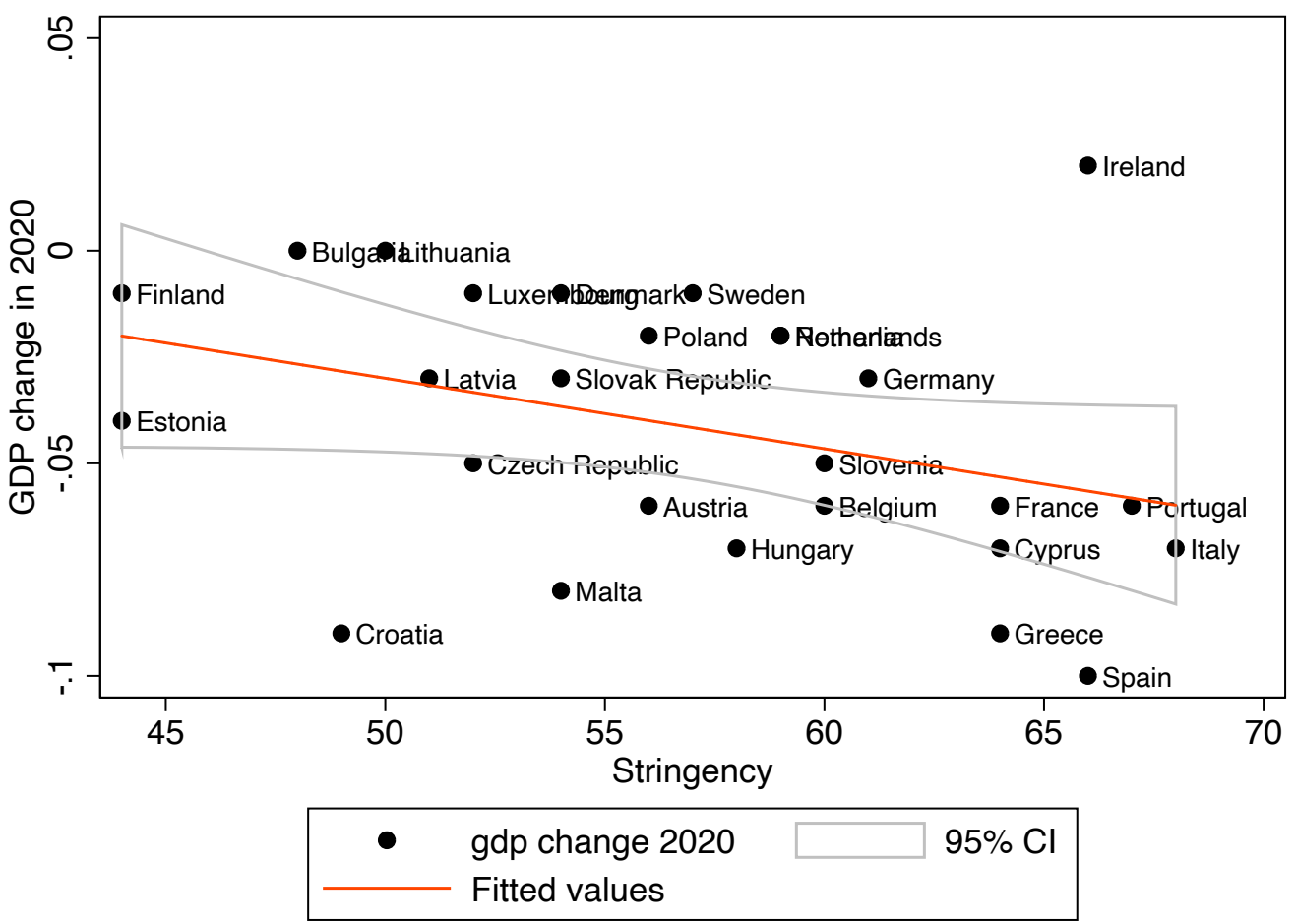

Figure A6 - Stringency index vs GDP change in 2020 across the EU27 


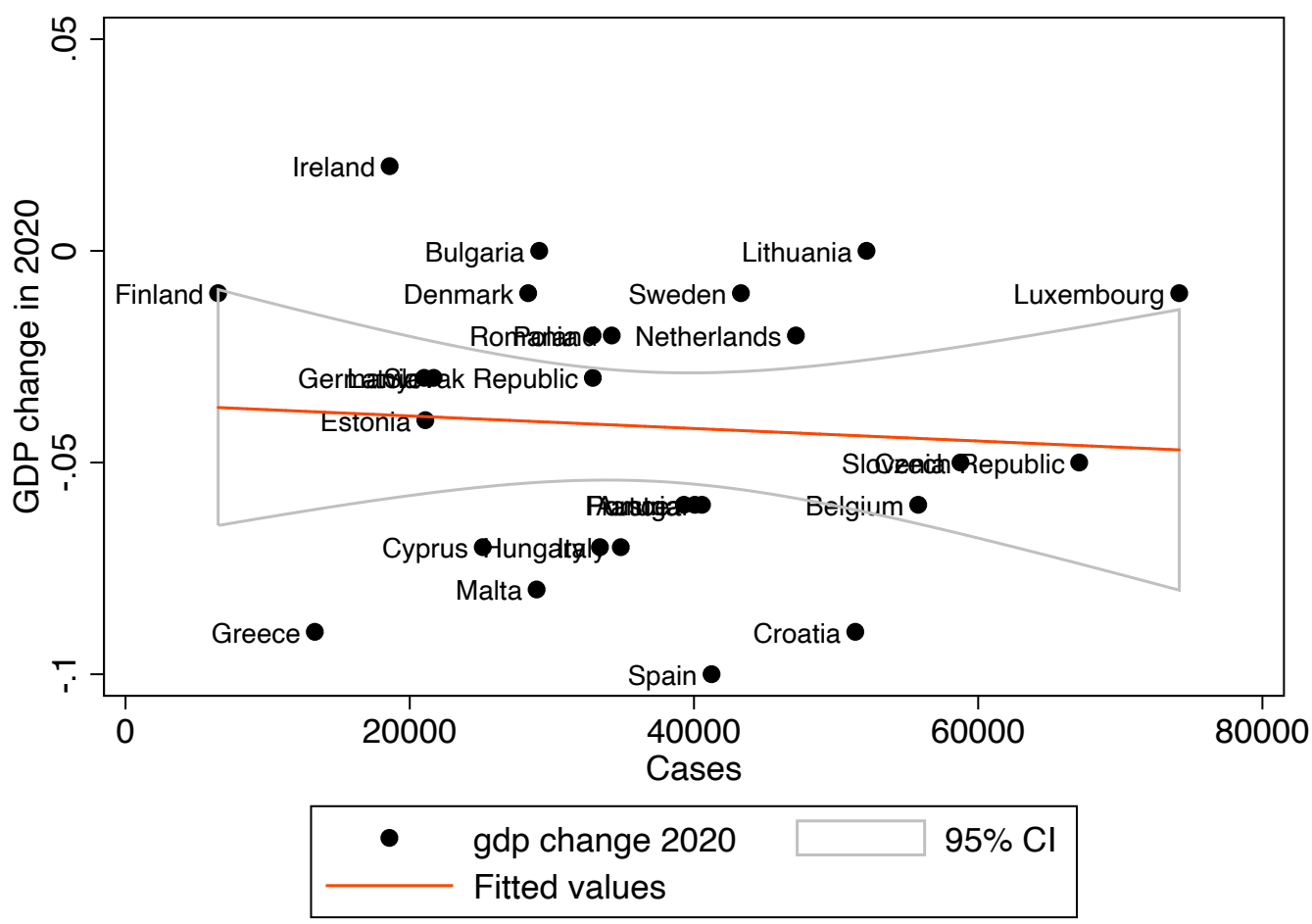

Figure A7 - Cases vs GDP change in 2020 across the EU27

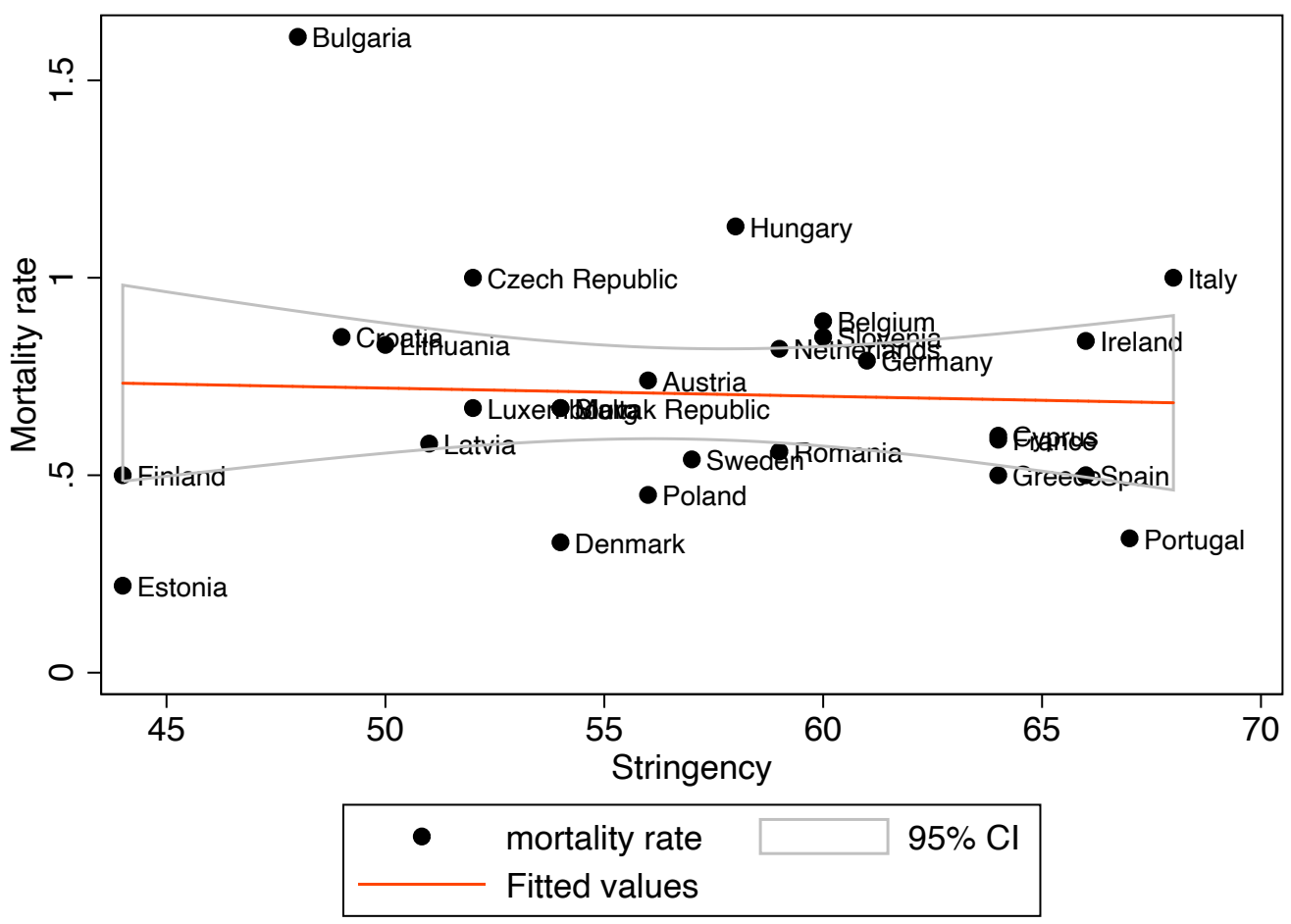

Figure A8 - Stringency index vs mortality rate across the EU27 
Table A1 - Scoreboard by wave

\begin{tabular}{|c|c|c|c|c|c|c|c|c|c|c|c|c|c|c|c|c|c|c|c|c|c|c|c|}
\hline $\begin{array}{l}\text { 辛 } \\
\text { 士 } \\
0 \\
0\end{array}$ & & & 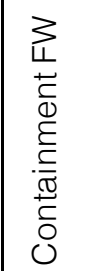 & & $\begin{array}{l}3 \\
\frac{1}{0} \\
\frac{0}{0} \\
0 \\
\frac{0}{0} \\
0\end{array}$ & & & 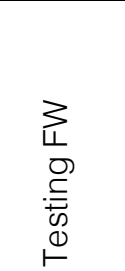 & 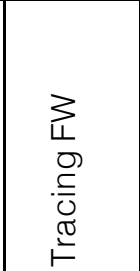 & $\begin{array}{l}3 \\
3 \\
\infty \\
0 \\
0 \\
0 \\
0\end{array}$ & 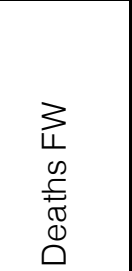 & 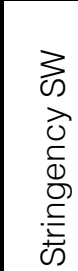 & & 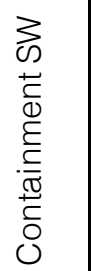 & $\begin{array}{l}3 \\
\text { on } \\
\text { D } \\
0 \\
\frac{8}{0} \\
0\end{array}$ & & 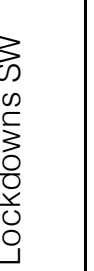 & 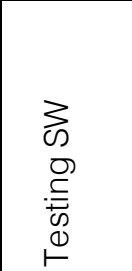 & & & & $\begin{array}{l}3 \\
\text { क } \\
\infty \\
\infty \\
\infty \\
\widetilde{D} \\
0\end{array}$ & 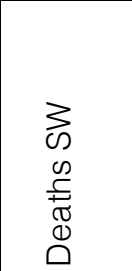 \\
\hline Austria & 0 & 53 & 5 & \begin{tabular}{l|l}
53 & 0 \\
\end{tabular} & 1.35 & 0 & 0.50 & 1.88 & $\begin{array}{|ll|} & 1.84 \\
\end{array}$ & $\begin{array}{lll}0 & 3047 \\
\end{array}$ & 81 & 0 & 6 & 664 & 1.55 & 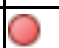 & 1.39 & $\begin{array}{ll}0 & 2.58 \\
\end{array}$ & J & 2.00 & & 37016 & 609 \\
\hline elgium & 0 & 62 & 05 & $57 \bar{C}$ & 1.52 & 0 & 1.18 & 1.65 & $\begin{array}{|lr|}0 & 1.64 \\
\end{array}$ & O 7355 & 0854 & 0 & 57 & 59 & 1.15 & 0 & 1.21 & 22.00 & 0 & 2.00 & & 8428 & 831 \\
\hline ulga & 0 & 50 & 04 & 43 & 2.33 & 0 & 0.61 & 0.96 & \begin{tabular}{|l|l|} 
& 1.36 \\
\end{tabular} & 2341 & 91 & 0 & 44 & 43 & (1.66 & 0 & 0.00 & \begin{tabular}{|l|l|} 
& 1.00 \\
\end{tabular} & 0 & 2.00 & & 6769 & 1000 \\
\hline ypru & 0 & 64 & 06 & 30 & 2.24 & 0 & 1.19 & 2.43 & $\begin{array}{|ll|} & 1.69 \\
\end{array}$ & $\begin{array}{|ll|} & 1699 \\
\end{array}$ & 23 & 0 & 63 & 66 & 1.55 & 0 & 1.55 & 3.00 & 0 & 2.00 & & 3440 & 113 \\
\hline iic & 0 & 49 & 5 & 50 & 1.72 & 0 & 63 & 1.82 & \begin{tabular}{|l|l|} 
& 2.00 \\
\end{tabular} & 2299 & 40 & 0 & 58 & 61 & 2.00 & 0 & 1.00 & 2.00 & 0 & 2.00 & & 309 & 1042 \\
\hline ierr & 0 & 1 & 05 & 58 & 2.20 & O & 57 & 22.36 & $\begin{array}{|lr|} & 1.52 \\
\end{array}$ & O 2922 & 111 & 0 & 1 & 660 & 01.28 & O & 0.86 & 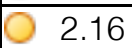 & O & 2.0 & & 91 & 292 \\
\hline en & 0 & 8 & 05 & $51 \mathrm{C}$ & 1.88 & $\sigma$ & 99 & O 2.28 & $\begin{array}{|ll|} & 1.00 \\
\end{array}$ & 3006 & 0108 & 0 & 47 & 48 & O 1.11 & 0 & 0.81 & 3.00 & 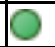 & 1. & & 28 & 11 \\
\hline pair & 0 & 65 & 5 & 5 & 2.34 & 0 & .40 & 1.64 & 1.00 & 9900 & 622 & 0 & 68 & 61 & 1.69 & 0 & 1.56 & 2.00 & J & 1.00 & & 42 & 46 \\
\hline sto & 0 & 46 & 14 & $40 \mid$ & 1.57 & 0 & 0.54 & 1.73 & $\begin{array}{|ll|}0 & 0.07 \\
\end{array}$ & 1790 & 48 & 0 & 40 & 39 & 1.30 & 0 & 0.00 & $\begin{array}{ll}0 & 2.00 \\
\end{array}$ & 0 & 1.00 & & 19310 & 124 \\
\hline \begin{tabular}{|l|} 
Finla \\
\end{tabular} & 0 & 46 & 104 & $\overline{42} \mathrm{C}$ & 1.22 & 0 & 0.42 & $\begin{array}{ll}0 & 1.29\end{array}$ & \begin{tabular}{|l|l|} 
& 1.00 \\
\end{tabular} & $\begin{array}{|ll|} & 1459 \\
\end{array}$ & 61 & 0 & 40 & 41 & 01.24 & 0 & 0.20 & 2.00 & O & 1.00 & & 5057 & 41 \\
\hline Franc & 0 & 66 & 06 & $31 \mathrm{C}$ & 1.98 & 1 & 0.83 & (1.91 & $\begin{array}{|ll|} & 1.61 \\
\end{array}$ & 4713 & (1) 450 & 0 & 61 & 65 & (1.67 & 0 & 1.25 & 3.00 & O & 2.00 & & 34579 & $\begin{array}{ll}0 & 501\end{array}$ \\
\hline Greec & P & 60 & 5 & 56 & 1.88 & 0 & 1.25 & 1.97 & \begin{tabular}{|l|l|} 
& 1.02 \\
\end{tabular} & $\begin{array}{|cc|} & 990 \\
\end{array}$ & 26 & 0 & 68 & 71 & 1.80 & 0 & 1.45 & 2.82 & 0 & 2.00 & & 12332 & 439 \\
\hline roa & 0 & 59 & 15 & $\begin{array}{l}57 \\
\end{array}$ & .19 & 0 & 15 & 0 & \begin{tabular}{|l|l|} 
& 2.00 \\
\end{tabular} & 2501 & 45 & 0 & 36 & 48 & 01.20 & 0 & 0.05 & 02.36 & 0 & 2.00 & & 356 & 910 \\
\hline Hun & 0 & 9 & 5 & 33 & 2.32 & 0 & 22 & 1.00 & $0 \quad 2.00$ & 635 & 64 & 0 & 56 & 53 & 1.43 & 0 & 1.02 & 1.66 & 0 & 1.68 & & 750 & 924 \\
\hline ela & 0 & 4 & 0 & \begin{tabular}{l|l}
56 & 0 \\
\end{tabular} & 2.44 & 1 & 11 & 59 & $\begin{array}{|ll|} & 1.48 \\
\end{array}$ & 5835 & 360 & $\mathrm{O}$ & 70 & 67 & O 1.77 & 0 & 1.52 & (2.00 & 0 & 2.00 & & 12752 & 0 \\
\hline aly & 0 & 69 & 06 & 370 & 3.00 & 0 & 27 & 2.00 & 02.00 & 44453 & 587 & 0 & 67 & 66 & 1.98 & 0 & 1.15 & 2.00 & 0 & 2.00 & & 399 & 640 \\
\hline Lithu & 0 & 50 & 104 & $45 \bar{C}$ & 1.82 & 0 & 64 & (1.84 & $\begin{array}{|ll|} & 1.60\end{array}$ & $\begin{array}{ll} & 1065 \\
\end{array}$ & 25 & 0 & 50 & 52 & 2.13 & 0 & 1.13 & 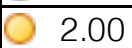 & 0 & 1.76 & & 080 & 634 \\
\hline Luxemb & 0 & 48 & 104 & $8 \mathrm{C}$ & 1.57 & 8 & 0.98 & 2.29 & $\begin{array}{ll} & 2.00 \\
\end{array}$ & 10583 & $\begin{array}{ll} & 198 \\
\end{array}$ & 0 & 58 & 57 & O 1.07 & 0 & $\begin{array}{l}1.52 \\
\end{array}$ & 13.00 & O & 2.00 & & 53565 & 593 \\
\hline \begin{tabular}{|l} 
Latvia \\
\end{tabular} & 0 & 54 & 05 & 52 & 2.80 & 0 & 0.93 & O 1.90 & $\begin{array}{|lr|}0 & 1.43 \\
\end{array}$ & $\begin{array}{lll} & 740 \\
\end{array}$ & 18 & 0 & 46 & 50 & (1.97 & 0 & 0.28 & 12.36 & O & 1.26 & & 20946 & 319 \\
\hline Malta & 0 & 57 & 5 & $\begin{array}{ll}58 \\
8\end{array}$ & 2.13 & 0 & 0.83 & 2.82 & \begin{tabular}{|l|l|} 
& 2.00 \\
\end{tabular} & 4265 & 27 & 0 & 49 & 57 & 1.00 & 0 & 0.00 & 3.00 & 0 & 2.00 & & 4666 & 469 \\
\hline Neth & 0 & 57 & 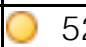 & $52 \mid$ & 1.74 & 0 & 21 & O 1.50 & $\begin{array}{|ll|} & 1.56 \\
\end{array}$ & 4274 & 365 & 0 & 61 & 57 & O 1.26 & 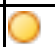 & 1.00 & 12.00 & 10 & 1.75 & & 2904 & 0 \\
\hline Pola & 0 & 57 & $\begin{array}{lll} & 4 \\
\end{array}$ & 49 & 2.28 & 7 & 0.38 & 1.38 & 0.83 & 1780 & 54 & 0 & 55 & 54 & 2.06 & 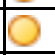 & 0.57 & 2.00 & O & 1.00 & & 2434 & 70 \\
\hline Port! & 0 & 69 & 06 & \begin{tabular}{l|l}
32 & \\
\end{tabular} & 2.22 & 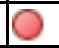 & 45 & O 2.65 & \begin{tabular}{|l|l|} 
& 1.04 \\
\end{tabular} & 5689 & $\begin{array}{ll} & 179 \\
\end{array}$ & 0 & 62 & 59 & 01.21 & 0 & 1.15 & 03.00 & 1 & 1.00 & & 4880 & 49 \\
\hline Rom & 10 & 59 & 0 & 8 & 2.34 & & 2 & O 1.57 & $\begin{array}{|ll|} & 0.84 \\
\end{array}$ & 4550 & $0 \quad 188$ & 0 & 0 & 56 & O 2.60 & 0 & 1.40 & 2.00 & 0 & 1.55 & & 8315 & 631 \\
\hline Slove & 0 & 3 & 0 & $\bar{\sigma}$ & 2.32 & $\overline{8}$ & 0.54 & 01.29 & \begin{tabular}{|l|l|} 
& 2.00 \\
\end{tabular} & 717 & -1 & 0 & 55 & 63 & 1.73 & 10 & 1.16 & 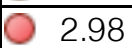 & 0 & 2.00 & & 2168 & 38 \\
\hline Slove & 1 & 54 & 05 & 540 & 1.68 & 0 & 0.33 & 1.97 & $\begin{array}{|lr|}0 & 1.97 \\
\end{array}$ & $\begin{array}{lll} & 1387 \\
\end{array}$ & 64 & 0 & 68 & 63 & 02.12 & 0 & 1.20 & 22.00 & O & 1.31 & & 57370 & 1233 \\
\hline Sweden & 0 & 56 & 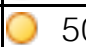 & 50 & 1.74 & 0 & \begin{tabular}{|c|}
0.87 \\
\end{tabular} & $\begin{array}{ll}1.48 \\
\end{array}$ & $\begin{array}{|ll|} & 1.12 \\
\end{array}$ & 8355 & 576 & 0 & 60 & 53 & 01.20 & 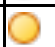 & 1.00 & 22.00 & O & 1.00 & & 34953 & 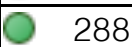 \\
\hline
\end{tabular}


Table A2 - Country and regional average across the PCA components

\begin{tabular}{|c|c|c|c|c|c|}
\hline & Comp1 & Comp2 & Comp3 & Comp4 & Comp5 \\
\hline Austria & 0.30 & 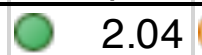 & -0.42 & 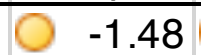 & -0.25 \\
\hline Belgium & 2.58 & 1.84 & -0.89 & 0.95 & 2.13 \\
\hline Bulgaria & -3.75 & 0.97 & -1.19 & 0.76 & 0.71 \\
\hline Cyprus & Or $\quad 0.94$ & $0-1.11$ & 2.38 & 0.68 & - -3.07 \\
\hline Czech Republic & -0.83 & 3.41 & -0.29 & -0.25 & 0.35 \\
\hline Germany & -0.25 & 0.34 & -0.21 & -1.65 & $\begin{array}{ll}0 & -0.27\end{array}$ \\
\hline Denmark & 1.58 & -2.27 & -1.08 & -1.70 & -0.09 \\
\hline Spain & 1.69 & O -1.65 & 0.51 & 2.20 & $\begin{array}{ll}0 & 2.60\end{array}$ \\
\hline Estonia & -1.60 & O $\quad-2.77$ & -1.97 & O -2.07 & O $\quad 0.11$ \\
\hline Finland & - & -2.37 & -3.51 & -1.64 & 0.00 \\
\hline France & 1.06 & 0.79 & 0.36 & 0.22 & 0.49 \\
\hline Greece & - 1.00 & -1.83 & 2.99 & 0.86 & -0.30 \\
\hline Croatia & -0.41 & 1.44 & 1.79 & -1.05 & 0.98 \\
\hline Hungary & -2.03 & 1.09 & 1.17 & 1.22 & O. 0.41 \\
\hline Ireland & 1.58 & -1.08 & -1.60 & 2.64 & -2.54 \\
\hline Italy & 0.60 & 0.31 & 1.80 & 1.00 & 2.37 \\
\hline Lithuania & -1.61 & 1.56 & -0.68 & $\begin{array}{ll}0 & -0.24\end{array}$ & $\begin{array}{ll}0 & -0.65\end{array}$ \\
\hline Luxembourg & 4.61 & 1.67 & -0.72 & 0.90 & - -2.57 \\
\hline Latvia & -2.52 & - -1.72 & 1.50 & 0.06 & - -0.64 \\
\hline Malta & 1.66 & 0.11 & 3.05 & O $\quad-4.19$ & - -0.52 \\
\hline Netherlands & O 2.11 & 0.46 & - $\quad-1.69$ & -0.79 & 0.75 \\
\hline Poland & - & -0.43 & -0.88 & 0.05 & $\begin{array}{ll}0.68 \\
0\end{array}$ \\
\hline Portugal & 1.01 & -2.36 & 2.45 & -0.15 & 1.33 \\
\hline Romania & -1.97 & -0.37 & 0.18 & 2.82 & - -0.44 \\
\hline Slovak Rep & -0.68 & 1.09 & -0.14 & 0.43 & $\begin{array}{ll}0 & -2.17\end{array}$ \\
\hline Slovenia & -1.06 & 2.61 & -0.72 & -0.51 & 0.42 \\
\hline Sweden & $\begin{array}{ll}1.70 \\
\end{array}$ & O -1.75 & $\begin{array}{ll}0 & -2.21 \\
\end{array}$ & $\begin{array}{ll}0 & 0.93 \\
\end{array}$ & 1.52 \\
\hline Core & 1.57 & $\begin{array}{ll} & -0.16 \\
\end{array}$ & -1.24 & -0.35 & 0.25 \\
\hline Periphery & 0.74 & -0.64 & 1.82 & -0.16 & $\begin{array}{ll}0.31 \\
\end{array}$ \\
\hline
\end{tabular}

